\title{
An Integrated Sensitivity Analysis Method for Energy and Comfort Performance of an Office Building along the Chinese Coastline
}

\author{
Ruijun Chen (D) and Yaw-Shyan Tsay *(D) \\ Department of Architecture, National Cheng Kung University, Tainan 701, Taiwan; N78083016@mail.ncku.edu.tw \\ * Correspondence: tsayys@mail.ncku.edu.tw; Tel.: +886-6-2757575 (ext. 54155)
}

check for updates

Citation: Chen, R.; Tsay, Y.-S. An Integrated Sensitivity Analysis Method for Energy and Comfort Performance of an Office Building along the Chinese Coastline. Buildings 2021, 11, 371. https://doi.org/ 10.3390/buildings11080371

Academic Editor: Gianpiero Evola

Received: 12 July 2021

Accepted: 19 August 2021

Published: 21 August 2021

Publisher's Note: MDPI stays neutral with regard to jurisdictional claims in published maps and institutional affiliations.

Copyright: (c) 2021 by the authors. Licensee MDPI, Basel, Switzerland. This article is an open access article distributed under the terms and conditions of the Creative Commons Attribution (CC BY) license (https:/ / creativecommons.org/licenses/by/ $4.0 /)$.

\begin{abstract}
This study aimed to evaluate the comprehensive percentage influence of input parameters on building energy and comfort performance by a new approach of sensitivity analysis (SA) and explore the most reliable and neutral sampling and sensitivity assessment method. The research combined 7 sampling methods with 13 SA methods to comprehensively integrate the percentage influence of 25 input parameters on building energy and comfort performance in 24 coastal cities of China. The results have found that the percentage influence of many important input parameters is affected by geographical position. Considering both energy and comfort performance of the building, the key parameters are heating setpoint, infiltration rate, cooling setpoint, roof U value, roof solar absorptance, window solar heat gain coefficient, equipment, and occupant density, all of which could comprehensively impact $70 \%$ of energy demand and comfort performance along the Chinese coastline. This is of great significance for policymakers to formulate relative building regulations. After comparing the F-test and the exceed percentage test, we recommended the Pearson with Quasi-random sampling method as the most reliable SA assessment method in building simulation, followed by the standardized regression coefficient in random sampling and Latin hypercube sampling methods, which can achieve data closest to the average value.
\end{abstract}

Keywords: sensitivity analysis; building energy consumption; sampling method; indoor comfort

\section{Introduction}

With the development of utilization and economy, buildings play a critical role in the maintenance of human society [1]. On one hand, buildings account for almost $40 \%$ of all energy consumption [2]. On the other hand, most people currently spend approximately $90 \%$ of their time inside buildings [3]. The desire to improve building energy efficiency and the built indoor environment is growing and is significantly influenced by the building envelope and building system. Furthermore, the building energy consumption of office buildings was predicted to be 10 to 20 times larger than that of residential buildings [4]. Therefore, improving building energy efficiency and thermal comfort in office buildings are urgent topics in the building sector [5].

However, for designers and engineers, the impacts of influential parameters in the early design stages of the building have not been systematically compared, and the key parameters with critical impacts are still unknown [6]. SA plays a key role in this area, which is a useful method for identifying the influential factors among complex building envelope systems [7]. The SA of influential variables in building energy performance (BEP) and a built environment is an important way to realize energy-saving design principles and confirm the priority measures of energy-saving and thermal comfort [8].

$\mathrm{BEP}$ research has increased rapidly in the past decades, and many software programs for building energy simulation have also been developed, such as DOE-2 [9], EnergyPlus [10,11], IES-Virtual Environment [12], ESP-r [13], and TRNSYS [14]. Simulation software can be combined with SA methods to evaluate the key design parameters for 
saving simulation time and improving energy efficiency [15]. The percentage influence (PI) of building parameters for energy consumption could continue to quantify, which is to evaluate the contribution rate of input parameters to influence the output $[16,17]$. The biggest influence factor is easy to identify, but the influence rates of other factors are quite different in different evaluation methods [18]. Meanwhile, the PI of each parameter can also contribute to building retrofit and optimization research [19]. It could not only identify the most appropriate retrofitting option for designers but also evaluate the optimal state of case building $[20,21]$.

Although considerable literature has been published around the theme of SA research, much of it has focused on the total energy consumption of a building, but not on district heating and cooling demands or indoor uncomfortable hours (IUH). The sensitivity of building parameters of building performance still needs to be researched in some detail [22] Meanwhile, various sampling and SA evaluation methods in the current research, as well as their ranking results, still differ. Therefore, the reliability of SA methods and the efficiency of the sampling method also require further research [16].

For policymakers, it is meaningful to identify the key parameters and improve the building energy-saving design and comfort performance to determine the best design in the early stage of the building design process. Policymakers can be guided to formulate the energy codes by providing sufficient information in selecting and processing building parameters that control changes in the energy demand. On the other hand, engineers and designers need to know both building engineering and energy models to correctly choose the influential building parameters [23]. Thus, all of them need relevant research to provide guidance.

In this paper, we aimed to calculate the exact PI of each input parameter on building energy and comfort performance through a new approach of SA, which was integrated through $27 \mathrm{SA}$ indices, including 6 sampling methods and $13 \mathrm{SA}$ methods. Then, for these $27 \mathrm{SA}$ indices, the study continued to explore the most reliable SA index as the recommended sampling and SA method through the methods of F-test and exceed percentage. The research was then applied to a real office building, and 25 input factors in 4 output parameters were investigated through the building performance simulation, including annual building energy consumption, IUH, district heating demand, and district cooling demand. Finally, 24 different weather locations along the coastal line of China were input to compare the influence of seaside weather on each parameter.

\section{Literature Review}

\subsection{Key Parameters for Building Performance}

The challenges of building envelope research mainly include SA of parameters, the robustness of the model, personalized optimization, and resilience in building envelope design [24]. Clearly, SA has been widely used in the research of building energy performance. Rui et al. [25] used SimLab and jEPlus software to investigate the influence of building design parameters on night cooling performance. The results show that the window to wall ratio (WWR), internal convective heat transfer coefficient, internal thermal mass level, and night mechanical air change rate are the biggest influential design parameters for night cooling. Amir et al. [23] carried out SA in thermal comfort and building energy consumption to evaluate the effect of light shelves characteristics in residential buildings. They found that the optimum light shelves were able to decrease $11.38 \%$ electrical energy consumption of the building. Yelin et al. [8] researched 24 parameters through standardized regression coefficient (SRC) in the building and detected key factors in energy loss. The study identified key parameters for improving net-zero energy buildings (NZEB) for grid interaction with limited power requirements.

Navid et al. [26] coupled MATLAB procedure with EnergyPlus through jEPlus and researched annual building energy consumption by both local sensitivity analysis (LSA) and global sensitivity analysis (GSA). The research found that three key factors affecting annual cooling energy use were window size, the orientation of the building, and the 
glazing solar transmittance. Similarly, Mauro et al. [27] combined EnergyPlus with MAT$\mathrm{LAB}$ and used standardized rank correlation coefficients (SRRC) to investigate a proper building retrofit plan. This study proposed that setpoint temperatures and glass type have the greatest influence on energy demand and thermal comfort. Rasouli et al. [28] used LSA to evaluate the impact of building and HVAC parameters through TRNSYS in small office buildings and indicated that ventilation rate had the largest impact on both annual heating and cooling consumption. Pannier et al. [29] identified the influential factors in building life cycle assessment using six different SA method factors and recommended Sobol indices. It can be noticed that the same parameters had different influence values for energy demand in different SA methods. Menberg et al. [30] compared three different sensitivity methods, including Morris, SRCs, and Sobol indices, for a building model in TRNSYS and proposed that the setpoint temperature and thermal capacitance had the largest computational cost. Vartholomaios [31] coupled EnergyPlus and SRRCs together and found that the high compactness and the southern orientation of the building could form low-energy combination.

\subsection{Sensitivity Analysis}

SA is a statistical method for energy simulation models and observational study and is capable of quantifying the contributions of different inputs' influence on the variability of the outputs. In the beginning of SA, sampling methods were needed to propagate the uncertainty of input parameters. Monte Carlo (MC) is a methodology that relies on repeated random sampling to generate numerical parameters probabilistically under different scenarios [32]. Random sampling (RS), Latin hypercube sampling (LHS), and Quasi-random sampling (QRS) are the three main sampling methods used in MC [33]. The RS method only samples parameters based on the Probability Density Function (PDF), which has uniform and normal distribution [34]. It is easy to utilize in SA with simple concepts and processes, but inefficient computation will appear if some sample points are sparsely distributed while others cluster closely. The LHS method is another methodology for producing a near-random sample of parameter values, between the RS and the stratified sampling technique, from multi-dimensional distribution [35]. LHS can generate more stable results than RS, but its drawbacks include space-filling and uncorrelated samples [36]. The Quasi-random subsequence is also known as the low-discrepancy sequence [37]. QRS produces the sample points by considering previous points, which can generate a significant convergence rate in MC simulation [38]. Morris sampling is only designed for Morris SA. Morris parameters are generated by the predefined PDF in the whole range of each parameter, and only one factor can vary at a time [39].

The methods for SA can be divided into two main categories, LSA and GSA [40,41]. Both methods are widely used in building performance analysis. LSA, also known as One-At-a-Time (OAT), is focused on varying only one design parameter at a time with other parameters fixed to evaluate the effect of uncertain parameters around a point [42]. Meanwhile, the GSA is based on changing all the design parameters at the same time and analyzing their impact on the entire input space. Although LSA can improve computation efficiency, the result depends highly on the central values of the design parameters and cannot estimate the uncertainty of the building model output [26]. Furthermore, the results of LSA in some research have been quite different from GSA. Therefore, it is not recommended to use the LSA method in the analysis of BEP [16]. GSA is regarded as a more effective and reliable method and has already been widely used in the research of important variables in BEP. Compared with LSA, the shortcomings of GSA are its high computational demands and that it is time consuming [43].

GSA can mainly be divided into regression $[30,44,45]$, variance-based $[26,46]$, screeningbased [30,39], and regional-based approaches $[47,48]$. The regression models are easy to implement and have a moderate computational cost for energy models, including the Pearson Correlation Coefficient (PEAR) [49], SRC [8], Partial Correlation Coefficient (PCC) [50], Spearman's Rank Correlation Coefficient (SPEA) [51], SRRC [52], and Partial Rank Cor- 
relation Coefficient (PRCC) [39]. The screening-based method is an extension of OAT. The variance-based method, also known as Analysis of Variance (ANOVA), is used to decompose the variance of the outputs into a sum of contributions of the inputs, which can be applied in nonmonotonic and nonlinear models [53]. The Fourier Amplitude Sensitivity Testing (FAST) method periodically samples the input data with sinusoidal function and has a Fourier transformation to quantify its contributions [54]. The Sobol method is similar to FAST but uses MC integration loops [29]. Morris is a type of screening approach that is a qualitative measure for ranking factors and is suitable for a large number of inputs [55]. However, it is a model-free method and is not suitable for uncertainty analysis. Regional sensitivity analysis (RSA) is also known as MC filtering and aims to identify the region of input range that relates to particular values of the output. The Kolmogorov-Smirnov (KS) test is a type of RSA and is suitable for any style of model outputs [43]. Table 1 summarizes the characteristics of these SA methods.

Table 1. The characteristics of each SA method in this study.

\begin{tabular}{|c|c|c|c|}
\hline Type & Method & Characteristics & Ref. \\
\hline \multirow{3}{*}{$\begin{array}{l}\text { Variance-based } \\
\text { sensitivity methods }\end{array}$} & Classic FAST & $\begin{array}{l}\text { FAST is a variance-based global } \\
\text { sensitivity analysis method; } \\
\text { computational complexity for a large } \\
\text { number of inputs; model-independent } \\
\text { approach; could not address } \\
\text { high-order interactions. }\end{array}$ & {$[30]$} \\
\hline & Extended FAST & $\begin{array}{l}\text { Extended FAST could address } \\
\text { high-order interactions. }\end{array}$ & {$[17]$} \\
\hline & $\begin{array}{l}\text { Sobol } \\
\text { indices }\end{array}$ & $\begin{array}{l}\text { Sobol is more robust than Classic and } \\
\text { Extended FAST; lower computational } \\
\text { efficiency; model-independent. }\end{array}$ & [29] \\
\hline \multirow{3}{*}{$\begin{array}{l}\text { Regression-based } \\
\text { sensitivity indices }\end{array}$} & PEAR & $\begin{array}{l}\text { PEAE is applied and is typically suitable } \\
\text { for linear models or systems; only } \\
\text { suitable for monotonic and } \\
\text { linear models. }\end{array}$ & [49] \\
\hline & SRC & $\begin{array}{l}\text { SRC provides the strength of the } \\
\text { correlation between } Y \text { and a given input } \\
X_{j} \text { with linear regression model; } \\
\text { highly efficient. }\end{array}$ & {$[8]$} \\
\hline & PCC & $\begin{array}{l}\text { PCC measures the sensitivity of } Y \text { to } X_{j} \\
\text { when the effects of the other inputs have } \\
\text { been cleaned; easy to implement. }\end{array}$ & [16] \\
\hline \multirow{3}{*}{$\begin{array}{l}\text { Regression-based } \\
\text { sensitivity indices } \\
\text { (rank transformation) }\end{array}$} & SPEA & $\begin{array}{l}\text { SPEA is nearly the same as PEAR but } \\
\text { uses the rank of data. }\end{array}$ & {$[51]$} \\
\hline & SRCC & $\begin{array}{l}\text { SRRC is used when the } \mathrm{R}^{2} \text { of SRC is low; } \\
\text { good for monotonic models. }\end{array}$ & {$[52]$} \\
\hline & PRCC & $\begin{array}{l}\text { PRCC is the PCC calculated on the rank } \\
\text { of input variables. }\end{array}$ & [39] \\
\hline Regional sensitivity methods & KS & $\begin{array}{l}\text { KS could identify the region in the input } \\
\text { space that corresponds to the particular } \\
\text { values of the output; a useful and } \\
\text { general non-parametric method. }\end{array}$ & [43] \\
\hline Screening-based method & Morris & $\begin{array}{l}\text { Morris only gives a new value to one } \\
\text { input parameter in each run; } \\
\text { model-independent approach; robust } \\
\text { and computationally efficient. }\end{array}$ & [55] \\
\hline
\end{tabular}

\section{Methodology}

\subsection{Framework}

Figure 1 shows the framework for this study. At the beginning of the research, the case building model was built by Grasshopper. Then we used seven different Monte-Carlo sampling methods in SimLab to establish input scenarios for EnergyPlus and jEPlus to 
simulate the annual total energy consumption, IUH, district heating demand, and district cooling demand of a building in 24 climate locations. Then, the simulation results were input back into SimLab for SA with 27 different indices, and all SA results were input into the influence index formula from Equations (1)-(3) to calculate the comprehensive value of PI, which could evaluate the influence of parameters more accurately compared with other studies. The following research was divided into two parts. In the first part, we evaluated the PI of each parameter on energy demands and IUH and determined their relationship with geographical locations. In the second part, we explored the reliable and neutral SA method by F-test and exceed percentage among $27 \mathrm{SA}$ indices.

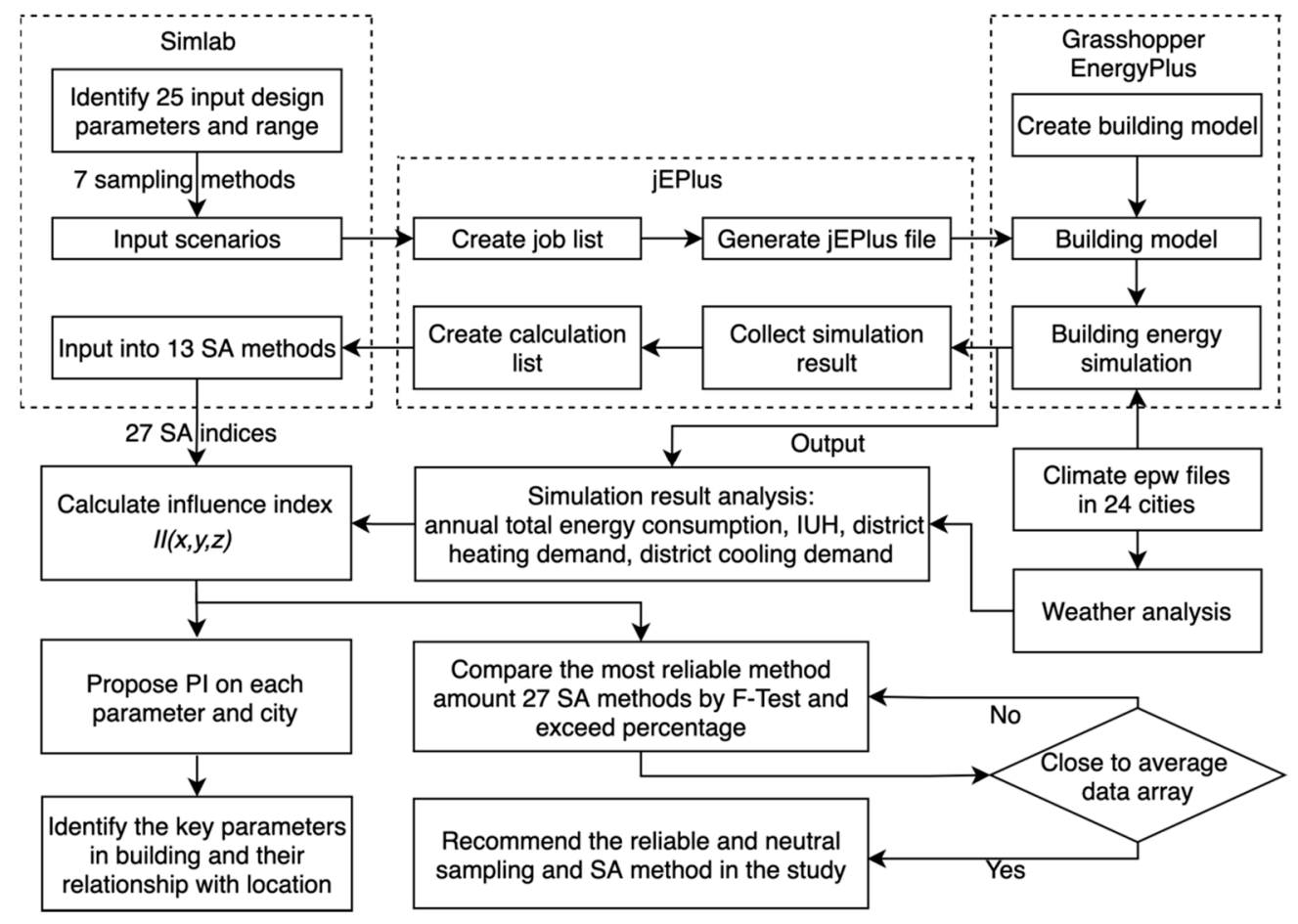

Figure 1. The research framework of this paper.

\subsection{Case Study}

The case building is a typical office building in the international academician park of Qingdao, China $\left(36^{\circ} 11^{\prime} \mathrm{N}, 120^{\circ} 29^{\prime} \mathrm{E}\right)$ that meets China's energy-saving building standards [56,57]. The details of the case building are shown in Table 2. This building is $36.7 \mathrm{~m}$ long, $16.6 \mathrm{~m}$ wide, and $22.2 \mathrm{~m}$ high, with six stories and a total area of $3741.7 \mathrm{~m}^{2}$. In this study, we selected Honeybee in Grasshopper from Software Rhino to build the model in Figure 2, in which $\mathrm{N}$ indicates the orientation as north. Four other office buildings with the same size are located around the case building, which were set up as opaque shadings in the building energy model.

Table 2. Building model form details.

\begin{tabular}{cc}
\hline Building Details & Value \\
\hline Dimension & $36.7 \times 16.6 \times 22.2 \mathrm{~m}$ (length $\times$ width $\times$ height) \\
Total area & $3741.7 \mathrm{~m}^{2}$ \\
Floors & 6 stories \\
Aspect ratio & 0.23 \\
Glazing area ratio & 0.31 (south); 0.25 (north); 0.04 (east); 0.03 (west) \\
Thermal zones & 9 per floor \\
\hline
\end{tabular}



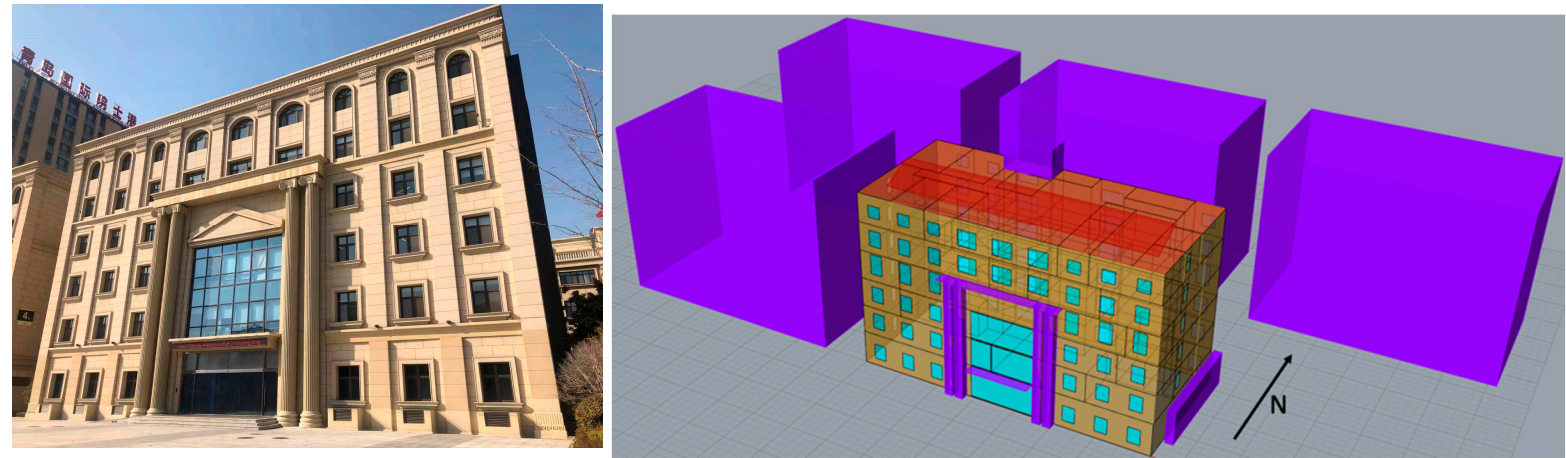

Figure 2. A real office building model in Qingdao, China.

Table 3 presents the list of input parameters and their variation range on the input space of the building model. Twenty-five parameters in the building envelope, internal gain, and system operation were researched in this building. The selection of input parameters was based on factors that have commonly been researched for the energy demand and comfort of buildings in the relevant literature [58-60]. We applied the ideal load air system to the model, and the people, lighting, and equipment schedules were set based on the statistic of the working schedule in the field, as shown in Figure 3. The lighting and equipment in the building gradually worked from 6 a.m. and closed at 8 p.m., with a lunch break between 12 a.m. and 1 p.m.
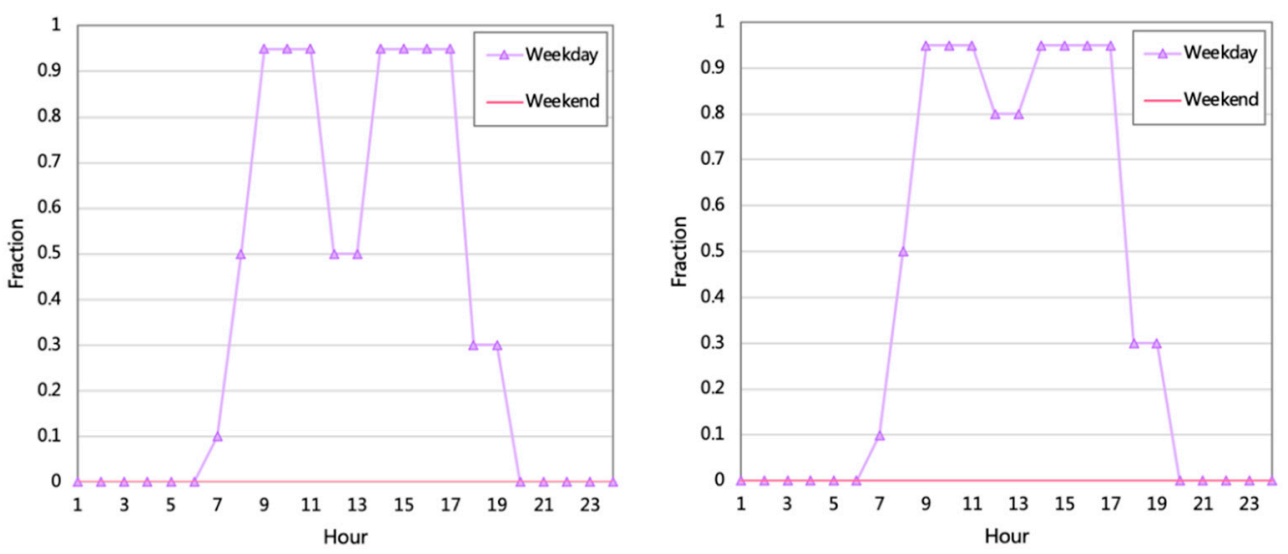

Figure 3. Schedule of lighting and people (right), schedule of equipment (left).

Afterward, the building model was simulated with the climate data of different locations to compare the changes of sensitivity in parameters. We selected these places from 24 cities along the eastern coastline of China, as shown in Figure 4, which are arranged from north to south with a change of serial number. According to the climatological zoning for buildings in the relevant standard [61], these cities belong to three climatic zones: Cold area (II), Hot summer and cold winter area (III), and Hot summer and warm winter area (IV). All information about these locations is shown in Table 4. 
Table 3. Input parameters for SA.

\begin{tabular}{|c|c|c|c|c|}
\hline Category & Parameter & Abbreviation & Range & Unit \\
\hline \multirow{18}{*}{ Building envelope } & Wall U value & Wall U & $0.14-0.8$ & $\mathrm{~W} /\left(\mathrm{m}^{2} \mathrm{~K}\right)$ \\
\hline & Wall solar absorptance & Wall SolarA & $0.1-0.9$ & \\
\hline & Wall thermal absorptance & Wall ThermalA & $0.1-0.9$ & \\
\hline & Wall visible absorptance & Wall VisibleA & $0.1-0.9$ & \\
\hline & Wall density & & $400-1250$ & $\mathrm{Kg} / \mathrm{m}^{3}$ \\
\hline & Roof U value & Roof U & $0.16-2$ & $\mathrm{~W} /\left(\mathrm{m}^{2} \mathrm{~K}\right)$ \\
\hline & Roof solar absorptance & Roof SolarA & $0.1-0.9$ & \\
\hline & Roof thermal absorptance & Roof ThermalA & $0.1-0.9$ & \\
\hline & Roof visible absorptance & Roof VisibleA & $0.1-0.9$ & \\
\hline & Roof density & & $700-1650$ & $\mathrm{Kg} / \mathrm{m}^{3}$ \\
\hline & Window U value & Window U & $1-6$ & $\mathrm{~W} /\left(\mathrm{m}^{2} \mathrm{~K}\right)$ \\
\hline & Window visible transmittance & Window VisibleT & $0.1-0.9$ & \\
\hline & Window solar heat gain coefficient & Window SHGC & $0.1-0.9$ & \\
\hline & Infiltration rate, $\mathrm{ACH}$ & & $0.1-0.8$ & $1 / \mathrm{h}$ \\
\hline & Window to wall ratio & WWR & $0.16-0.4$ & \\
\hline & Building orientation & Orientation & $0-360$ & \\
\hline & Overhang projection ratio & Overhang ratio & $0.05-0.6$ & \\
\hline & Equipment & & 4-12 & $\mathrm{W} / \mathrm{m}^{2}$ \\
\hline \multirow{4}{*}{ Internal gain } & Light & & $2-7$ & $\mathrm{~W} / \mathrm{m}^{2}$ \\
\hline & Occupant density & & $0.02-0.15$ & $\mathrm{Psn} / \mathrm{m}^{2}$ \\
\hline & Occupant fraction radiant & Occupant FR & $0.25-0.4$ & \\
\hline & Occupant sensible heat fraction & Occupant SH & $0.45-0.68$ & \\
\hline \multirow{3}{*}{ System operation } & Heating setpoint & & $18-22.5$ & ${ }^{\circ} \mathrm{C}$ \\
\hline & Cooling setpoint & & $23.5-28$ & ${ }^{\circ} \mathrm{C}$ \\
\hline & Outdoor air flow rate & Outdoor Air FlowR & $0-0.03$ & $\mathrm{~m}^{3} / \mathrm{s} / \mathrm{psn}$ \\
\hline
\end{tabular}

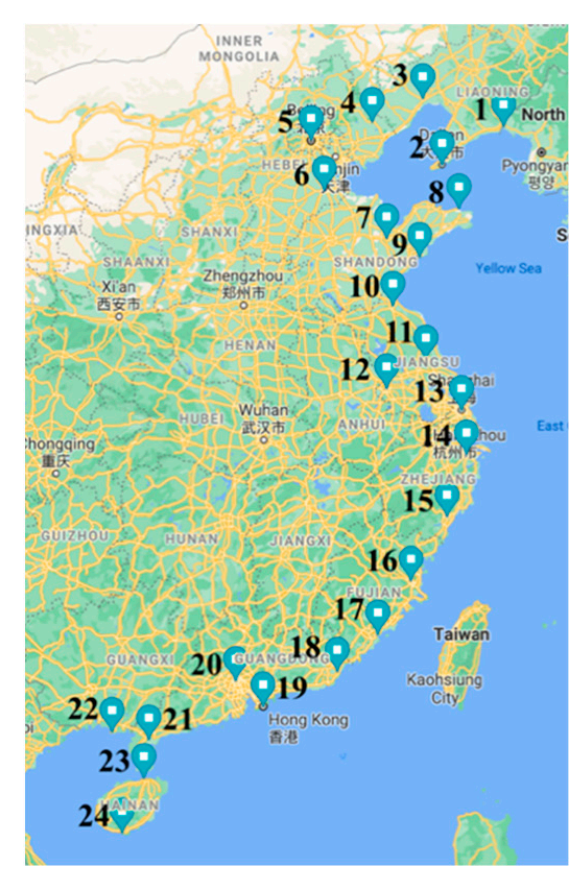

Figure 4. Twenty-four locations on a map of China. 
Table 4. Characteristics of cities in this study.

\begin{tabular}{cccccc}
\hline No. & Location & Latitude & Longitude & Elevation & Climate Zone \\
\hline 1 & Dandong & $40.05^{\circ} \mathrm{N}$ & $124.33^{\circ} \mathrm{E}$ & $14 \mathrm{~m}$ & II \\
2 & Dalian & $38.90^{\circ} \mathrm{N}$ & $121.63^{\circ} \mathrm{E}$ & $97 \mathrm{~m}$ & II \\
3 & Jinzhou & $41.10^{\circ} \mathrm{N}$ & $121.13^{\circ} \mathrm{E}$ & $70 \mathrm{~m}$ & II \\
4 & Qinglong & $40.40^{\circ} \mathrm{N}$ & $118.95^{\circ} \mathrm{E}$ & $228 \mathrm{~m}$ & II \\
5 & Beijing & $39.93^{\circ} \mathrm{N}$ & $116.28^{\circ} \mathrm{E}$ & $55 \mathrm{~m}$ & II \\
6 & Cangzhou & $38.33^{\circ} \mathrm{N}$ & $116.83^{\circ} \mathrm{E}$ & $11 \mathrm{~m}$ & II \\
7 & Weifang & $36.77^{\circ} \mathrm{N}$ & $119.18^{\circ} \mathrm{E}$ & $22 \mathrm{~m}$ & II \\
8 & Weihai & $37.50^{\circ} \mathrm{N}$ & $122.12^{\circ} \mathrm{E}$ & $47 \mathrm{~m}$ & II \\
9 & Qingdao & $36.07^{\circ} \mathrm{N}$ & $120.33^{\circ} \mathrm{E}$ & $77 \mathrm{~m}$ & II \\
10 & Ganyu & $34.83^{\circ} \mathrm{N}$ & $119.13^{\circ} \mathrm{E}$ & $10 \mathrm{~m}$ & II \\
11 & Dongtai & $32.87^{\circ} \mathrm{N}$ & $120.32^{\circ} \mathrm{E}$ & $4 \mathrm{~m}$ & III \\
12 & Nanjing & $32.00^{\circ} \mathrm{N}$ & $118.80^{\circ} \mathrm{E}$ & $7 \mathrm{~m}$ & III \\
13 & Shanghai & $31.17^{\circ} \mathrm{N}$ & $121.43^{\circ} \mathrm{E}$ & $3 \mathrm{~m}$ & III \\
14 & Ningbo & $29.83^{\circ} \mathrm{N}$ & $121.47^{\circ} \mathrm{E}$ & $4 \mathrm{~m}$ & III \\
15 & Wenzhou & $28.02^{\circ} \mathrm{N}$ & $120.67^{\circ} \mathrm{E}$ & $7 \mathrm{~m}$ & III \\
16 & Fuzhou & $26.08^{\circ} \mathrm{N}$ & $119.28^{\circ} \mathrm{E}$ & $84 \mathrm{~m}$ & IV \\
17 & Xiamen & $24.48^{\circ} \mathrm{N}$ & $118.07^{\circ} \mathrm{E}$ & $139 \mathrm{~m}$ & IV \\
18 & Shantou & $23.40^{\circ} \mathrm{N}$ & $116.68^{\circ} \mathrm{E}$ & $3 \mathrm{~m}$ & IV \\
19 & Guangzhou & $23.17^{\circ} \mathrm{N}$ & $113.33^{\circ} \mathrm{E}$ & $41 \mathrm{~m}$ & IV \\
20 & Hong Kong & $22.31^{\circ} \mathrm{N}$ & $113.92^{\circ} \mathrm{E}$ & $8.5 \mathrm{~m}$ & IV \\
21 & Zhanjiang & $21.15^{\circ} \mathrm{N}$ & $110.30^{\circ} \mathrm{E}$ & $53 \mathrm{~m}$ & IV \\
22 & Beihai & $21.45^{\circ} \mathrm{N}$ & $109.13^{\circ} \mathrm{E}$ & $13 \mathrm{~m}$ & IV \\
23 & Haikou & $20.00^{\circ} \mathrm{N}$ & $110.25^{\circ} \mathrm{E}$ & $64 \mathrm{~m}$ & IV \\
24 & Sanya & $18.23^{\circ} \mathrm{N}$ & $109.52^{\circ} \mathrm{E}$ & $6 \mathrm{~m}$ & IV \\
\hline
\end{tabular}

\subsection{Sensitivity Analysis}

\subsubsection{Sensitivity Analysis Methods}

In the early stage of the building design process, it is important to identify the key parameters and improve the building energy-saving and comfort performance for the best design. Thus, the SA methods are applied in our study to calculate the PI of input factors.

Since the uncertainty on the probabilistic distribution for input parameters is an important process for SA, we adopted SimLab in this study. This software is designed for uncertainty and SA using the Monte Carlo method, which generates samples based on the input design parameters. The 25 parameters and their ranges in Table 3 were input into SimLab and generated the discreet values by seven different sampling methods, including FASTC, FASTE, Sobol, RS, LHS, QRS, and Morris.

For sampling these input parameters, FASTC and FASTE samples were performed 14,249 and 1625 times, respectively: Sobol samples 1664 times; RS, LHS, and QRS samples 1024 times individually; and Morris samples 260 times; therefore, the computer needed to execute 20,870 intermediate data format (IDF) files per city. At last, $j E P l u s$ received the input parameter sampling from SimLab and used the model built by EnergyPlus to carry out parametric simulations. The computers used in this study were two ASUSPRO D840MB, with an Intel Core i7-8700 12-logical-core, an 8 GB random-access memory (RAM), and a hard disk drive of 1 TB storage. The execution of 542,620 IDF files lasted about four months.

After that, the simulation results were transferred back to SimLab and calculated using SA methods. As shown in Table 4, 13 SA methods were applied in this study, including classic Fourier Amplitude Sensitivity Testing (FAST), extended FAST (first order and total order), Sobol (first order and total order), PEAR, SPEA, PCC, PRCC, SRC, SRRC, KS, and Morris. Furthermore, three sampling methods (RS, LHS, QRS) were used in this paper, which were individually evaluated using PEAR, SPEA, PCC, PRCC, SRC, SRRC, and KS. Therefore, pursuant to the 7 sampling methods and 13 SA methods, this study proposed 27 different SA indices for each influence parameter. 


\subsubsection{Percentage Influence}

In many studies, the PI of input parameters were different in different SA methods [16]. Thus, this research generated $27 \mathrm{SA}$ indices and integrated them together to calculate the mean PI. To evaluate the comprehensive PI among these SA values in each city, the values of the SA index in the same method were input into Equation (1), and the sensitivity index $S I_{(x, y, z)}$ of their effect was calculated. Then, the mean sensitivity percentage among the $27 \mathrm{SA}$ indices was proposed in Equation (3).

The sensitivity index $S I_{(x, y, z)}$ was proposed in Equation (1), which could represent the sensitivity percentage for SA index $(x)$, input parameter $(y)$, and location $(z)$ :

$$
S I_{(x, y, z)}=\frac{\left|m_{(x, y, z)}\right|}{\sum_{x=1}^{x=a}\left|m_{(x, y, z)}\right|}
$$

where $m_{(x, y, z)}$ is the result value of each SA index; $\mathrm{x}$ is the order of SA index, $x=1,2, \ldots$, $27 ; y$ means the order of input parameter, $y=1,2, \ldots, 25 ; z$ represents the order of location in Table $4, z=1,2,3, \ldots, 24$; and $a$ is the total number of influence factor and is equal to 25 .

Therefore, the $S I_{(x, y, z)}$ with different parameters and methods in the same location can be shown as a SI matrix in Equation (2). The row means SI in the same parameter and different SA indices, while the column shows the SI in the same SA index and different SI.

$$
S I=\left[\begin{array}{ccc}
S I_{(1,1, z)} & \cdots & S I_{(27,1, z)} \\
\vdots & \ddots & \vdots \\
S I_{(1,25, z)} & \cdots & S I_{(27,25, z)}
\end{array}\right]
$$

The percentage influence index $P I_{(x, y, z)}$ of each input parameter was proposed in Equation (3), which represents the average PI of each parameter based on the 27 SA indices:

$$
P I_{(x, y, z)}=\frac{1}{b} \sum_{y=1}^{y=b} S I_{(x, y, z)}
$$

where the $S I_{(x, y, z)}$ is the sensitivity percentage in Equation (1), and $b$ is the total number of SA indices and is equal to $27 ; P I_{(x, y, z)}$ can be seen as the average value of the row in matrix SI.

\subsubsection{F-Test and Exceed Percentage}

Because many studies did not compare a variety of sampling and SA methods for building energy modeling, this study adopted the methods of F-test and exceed percentage to explore the most reliable SA index as the recommended sampling and SA method among the $27 \mathrm{SA}$ indices [30]. In previous studies, the Analysis of Variance (ANOVA) used the F-test to determine whether there were significant differences between the mean responses of main effects or interactions between factors. The relative magnitude of $\mathrm{F}$ values can be used to rank the factors in SA. The higher the F value is, the more sensitive the response variable is to the factor. Therefore, factors with higher $\mathrm{F}$ values have a higher ranking. If the F-test value was closer to 1 , the two data sets were closer to each other. The closer the value was to 0 , the more different the two sets of data were. Therefore, to find the most reliable and neutral influence assessment method, the F-test is applied to distinguish the data set closest to the average value among the $27 \mathrm{SA}$ indices.

In the F-test, the $X=\left\{X_{1}, \ldots, X_{n}\right\}$ and $Y=\left\{Y_{1}, \ldots, Y_{m}\right\}$ are independent and identically distributed samples from two data arrays that each have a normal distribution. The influence index $P I_{(x, y, \bar{z})}$ of each SA index is applied to $X$, which averages the $P I_{(x, y, z)}$ values of all locations, while the average value of influence index $P I_{(x, y, \bar{z})}$ in all SA indices is applied to $Y$. In the F-test, the $\bar{X}$ and $\bar{Y}$ are the mean values of the data array, as shown in Equations (4) and (5).

$$
\bar{X}=\frac{1}{n} \sum_{i=1}^{n} X_{i}
$$




$$
\bar{Y}=\frac{1}{m} \sum_{i=1}^{m} Y_{i}
$$

Then, the variances of both data arrays are calculated in Equations (6) and (7).

$$
\begin{aligned}
& S_{X}^{2}=\frac{1}{n-1} \sum_{i=1}^{n}\left(X_{i}-\bar{X}\right)^{2} \\
& S_{Y}^{2}=\frac{1}{m-1} \sum_{i=1}^{m}\left(Y_{i}-\bar{Y}\right)^{2}
\end{aligned}
$$

Then, the test statistic F value is calculated by the variance of data array in Equation (8).

$$
\mathrm{F}=\frac{S_{X}^{2}}{S_{Y}^{2}}
$$

If the variances have the same value, the F-distribution with $(n-1)$ and $(m-1)$ degrees of freedom is obtained. Otherwise, it will follow an F-distribution scaled by the true variance ratio.

The exceed percentage (EP) of the influence index is the cumulative percentage difference between the influence index value $P I_{(x, y, z)}$ of the parameters in each method and the average value $M_{m}^{y}$ of the parameters in all methods. To obtain a general and extensive result, all the values in EP are the average values at all locations, which is represented by $P I_{(x, y, \bar{z})}$ in Equation (9). The equation of $E P$ is:

$$
\begin{gathered}
P I_{(x, y, \bar{z})}=\frac{1}{c} \sum_{z=1}^{z=24} P I_{(x, y, z)} \\
M_{m}^{y}=\frac{1}{b} \sum_{x=1}^{x=27} P I_{(x, y, \bar{z})} \\
E P_{x}=\sum_{y=1}^{y=25}\left|P I_{(x, y, \bar{z})}-M_{m}^{y}\right|
\end{gathered}
$$

where $x$ is the order of SA index, $x=1,2, \ldots, 27 ; y$ means the order of input parameter, $y=1,2, \ldots, 25 ; z$ represents the order of location in Table $4, z=1,2,3, \ldots, 24 ; a$ is the total number of influence factor and is equal to $25 ; b$ is the total number of SA indices in this study and is equal to $27 ; c$ is the total location number and is equal to $24 ; E P_{x}$ means the exceed percentage value in method $x$; and $M_{m}^{y}$ does not change with method $x$ in Equation (11).

\section{Results and Analysis}

\subsection{Weather Analysis}

The first step of our research was to analyze the climate data of these 24 coastal cities, which were taken from EPW climate files, and then compare dry bulb temperature (DBT), relative humidity (RH), global horizontal radiation (GHR), heating degree day (HDD), and cooling degree day (CDD), respectively.

The order of location in the chart was arranged according to the longitude and latitude in Table 4, from north to south. In Figure 5, the DBT clearly changes with the longitude and latitude of the geographical location, and the overall average DBT was found to rise from $10.8{ }^{\circ} \mathrm{C}$ in Dandong to $27^{\circ} \mathrm{C}$ in Sanya. Then, again in Figure 5, since all the cities were chosen from the coastline, the $\mathrm{RH}$ of these cities had a consistently high value, but the average $\mathrm{RH}$ increased with southward location, rising from nearly $50 \%$ in Jinzhou to almost $80 \%$ in Haikou. The third diagram in Figure 5, representing the GHR, shows that the overall level of GHR is almost the same and is not significantly affected by latitude and longitude. The average value remained between $300-400 \mathrm{~W} / \mathrm{m}^{2}$, and the maximum value was about $1000 \mathrm{~W} / \mathrm{m}^{2}$. The last weather analysis chart is the HDD and CDD. The base temperatures for HDD and CDD were $18{ }^{\circ} \mathrm{C}$ and $26^{\circ} \mathrm{C}$, respectively. The changing trend of HDD with geographical location is clear, from 3566 in Dandong to almost 0 in the 
Sanya. In contrast, the CDD increased when moving southward, from 6 to 498 at the end. It needs to be mentioned that the value of HDD in the northernmost city is several times larger than the $\mathrm{CDD}$ value in the southernmost city.

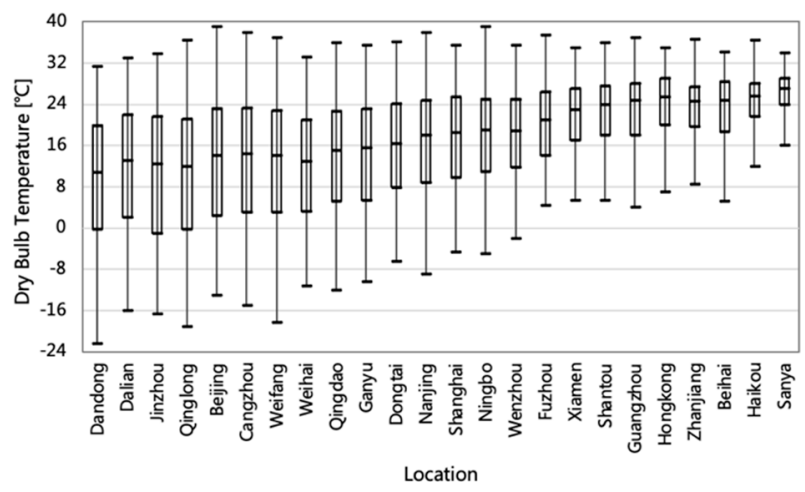

(a)

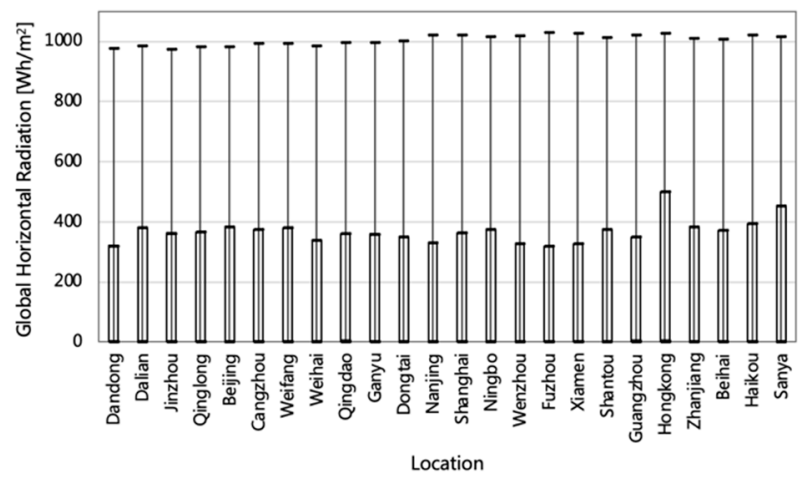

(c)

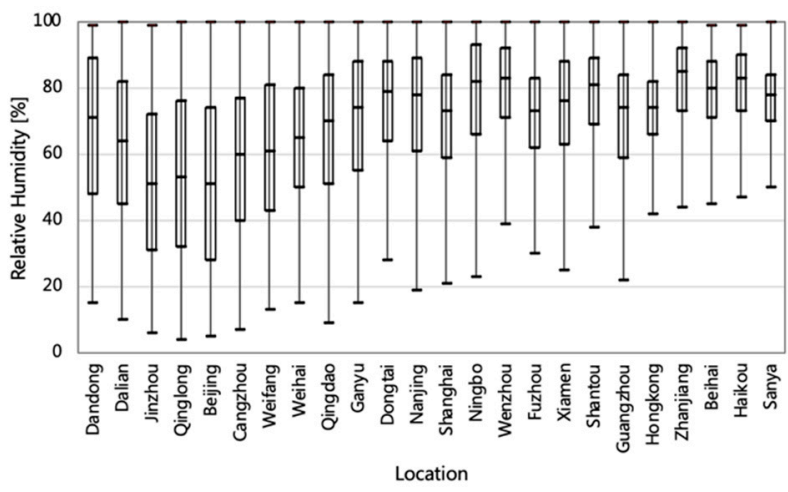

(b)

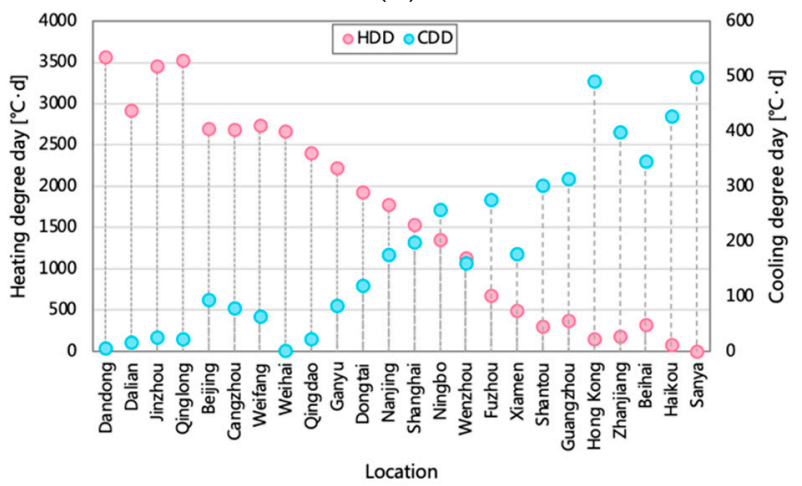

(d)

Figure 5. Analysis of EPW weather data in 24 coastal cities: (a) DBT; (b) RH; (c) GHR; (d) HDD and CDD.

\subsection{Analysis of Simulation Results in Different Locations}

After analyzing the climate data, the box chart was used to compare the simulation results of different locations, including annual total building energy consumption, annual district heating demand, annual district cooling demand, and annual IUH, in order to observe the impact of the climate conditions of different latitude on their simulation output. The results of the simulated data from all seven sampling methods in each city were synthesized and are shown in the box chart. In the next section, these values are imported into their corresponding SA and then compared with the influence of each parameter. Since we evaluated the PI of each input parameter on the output value by corresponding SA methods in the next section, this step could show the weight of input parameters in output value more comprehensively. The first chart in Figure 6 shows the comparison of the annual total building energy consumption of the building in each place. Of particular note, the average value of each city decreases from north to south with the change of latitude. Jinzhou is the northernmost city, so the maximum average value of energy consumption is $135 \mathrm{kWh} / \mathrm{m}^{2}$. From Dandong to Weihai, the average value changes are small, keeping around $125 \mathrm{kWh} / \mathrm{m}^{2}$. However, the downward trend of total energy consumption only lasted until Wenzhou, and then its average value in the following cities began to be almost the same, floating around $80 \mathrm{kWh} / \mathrm{W}^{2}$. 


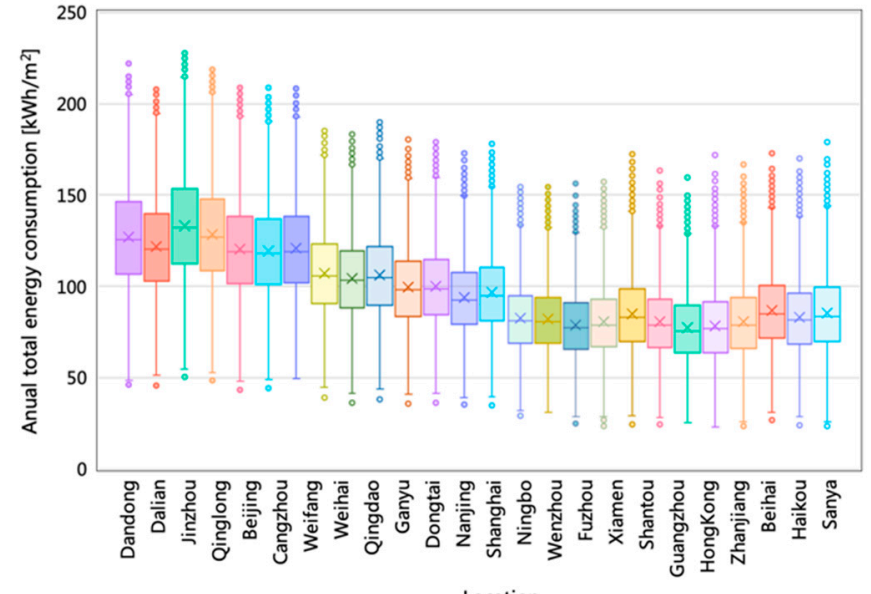

(a)

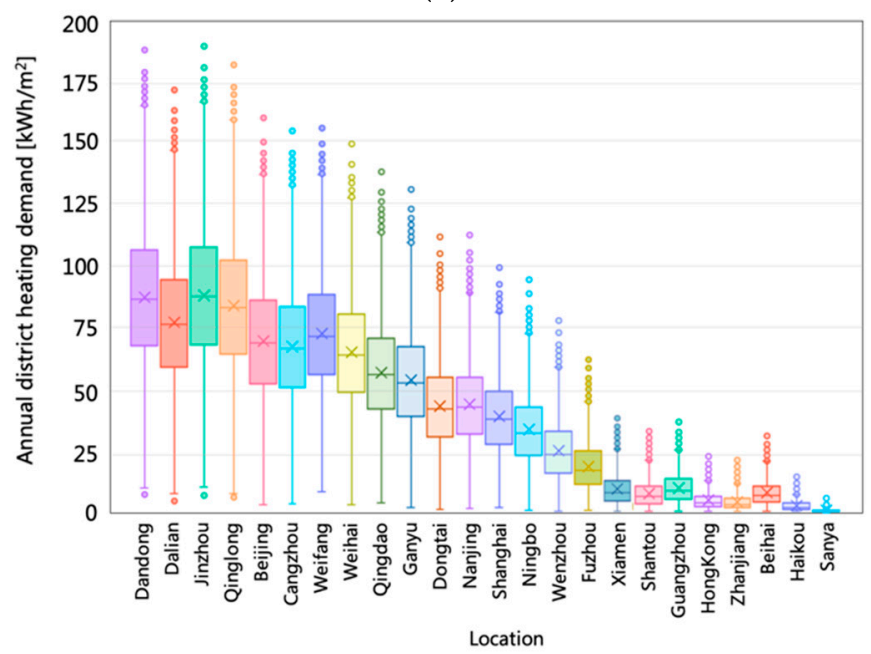

(c)

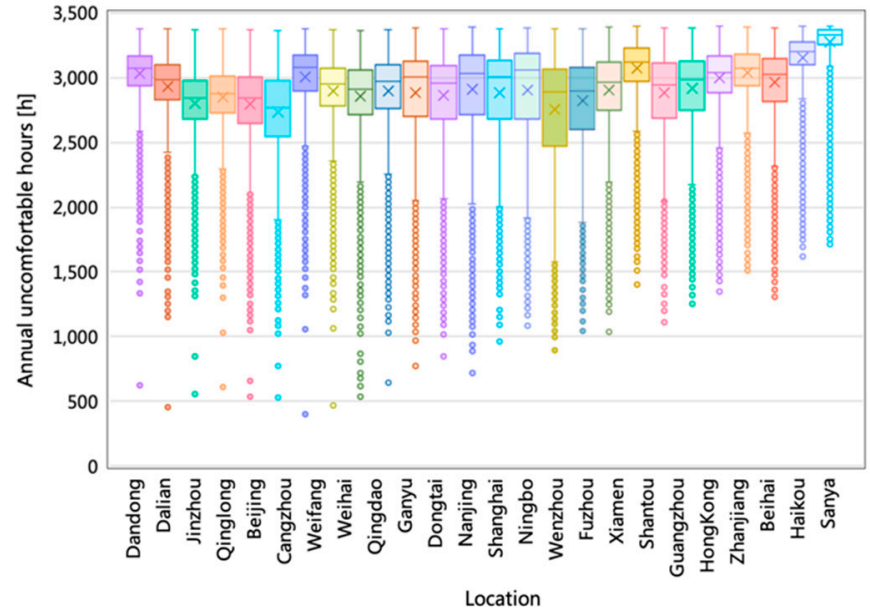

(b)

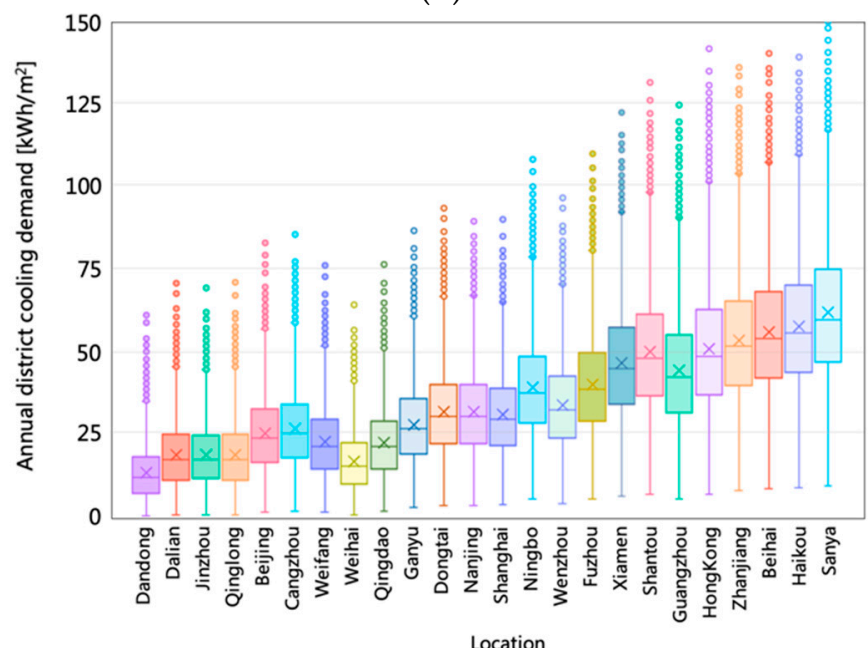

(d)

Figure 6. Simulation results of the building in 24 coastal cities: (a) annual total building energy consumption; (b) IUH; (c) district heating demand; (d) district cooling demand.

The second output is the IUH, shown in Figure 6b, which is evaluated according to the ASHRAE 55-2004 standard. The chart shows that the maximum IUH of buildings in each city has the same value, $3300 \mathrm{~h}$, but their average value and upper and lower quartile differed. Meanwhile, although the changing law of IUH is not pursuant to latitude, it is worth noting that northern cities have more extreme values of less than $1000 \mathrm{~h}$ of discomfort, which are gradually increased with the latitude from north to south. In Sanya, the value of IUH is the largest among the 24 cities, as high as $3300 \mathrm{~h}$, and the change range of upper and lower quantile value is the smallest, which shows that the IUH of the building is longer in the climate conditions of Sanya.

Then, we analyzed the annual total district heating and cooling demand. The annual total energy consumption of the building can be divided into three parts: district heating demand, district cooling demand, and interior equipment energy demand. As shown in Figure $6 c$, the upper and lower quartile range and average value in the annual district heating demand change significantly with latitude. The average value of Dandong in the northernmost area is the largest, reaching $89.9 \mathrm{kWh} / \mathrm{m}^{2}$, and then decreases from north to south with latitude, dropping to almost $0 \mathrm{kWh} / \mathrm{m}^{2}$ in Sanya. Therefore, the district heating demand is greatly affected by climate conditions. At the same time, starting from Xiamen, the average values of the later cities tend to be close to 0 , and the upper and lower quartile range become almost the same, thus indicating that the change of annual district heating demands of buildings after the climate of Xiamen is very small. The southern cities are 
warm enough in winter and do not have too much district heating demands, while the cities in the north are colder in winter and consume considerable heating energy.

The annual district cooling demand is shown in Figure 6d, which has the opposite trend of heating energy demand from north to south. The average value in the northernmost area was $13.1 \mathrm{kWh} / \mathrm{m}^{2}$, which continued rising until it reached the maximum value of $61.2 \mathrm{kWh} / \mathrm{m}^{2}$ in Sanya. This finding indicates that the climate in the north is colder, and the district cooling demand is low in summer, while the temperature in the south is higher in summer, so reducing the temperature with air conditioning is necessary. The change and usage of district cooling demands are not as big as heating energy consumption.

\subsection{Percentage Influence of Input Parameters}

After analyzing the simulated output values, the output data of different sampling methods were input into the corresponding sensitivity methods for SA analysis to synthesize the $27 \mathrm{SA}$ indices with the formulas in the methods to obtain the results of the SA index shown in Figures 7-10. The results show the percentages of 25 building impact parameters in 24 different cities. This index integrates the results of $27 \mathrm{SA}$ evaluation methods, which could reduce the impact of extreme values on the results and accurately express the percentage of the building factor's impact on energy consumption.

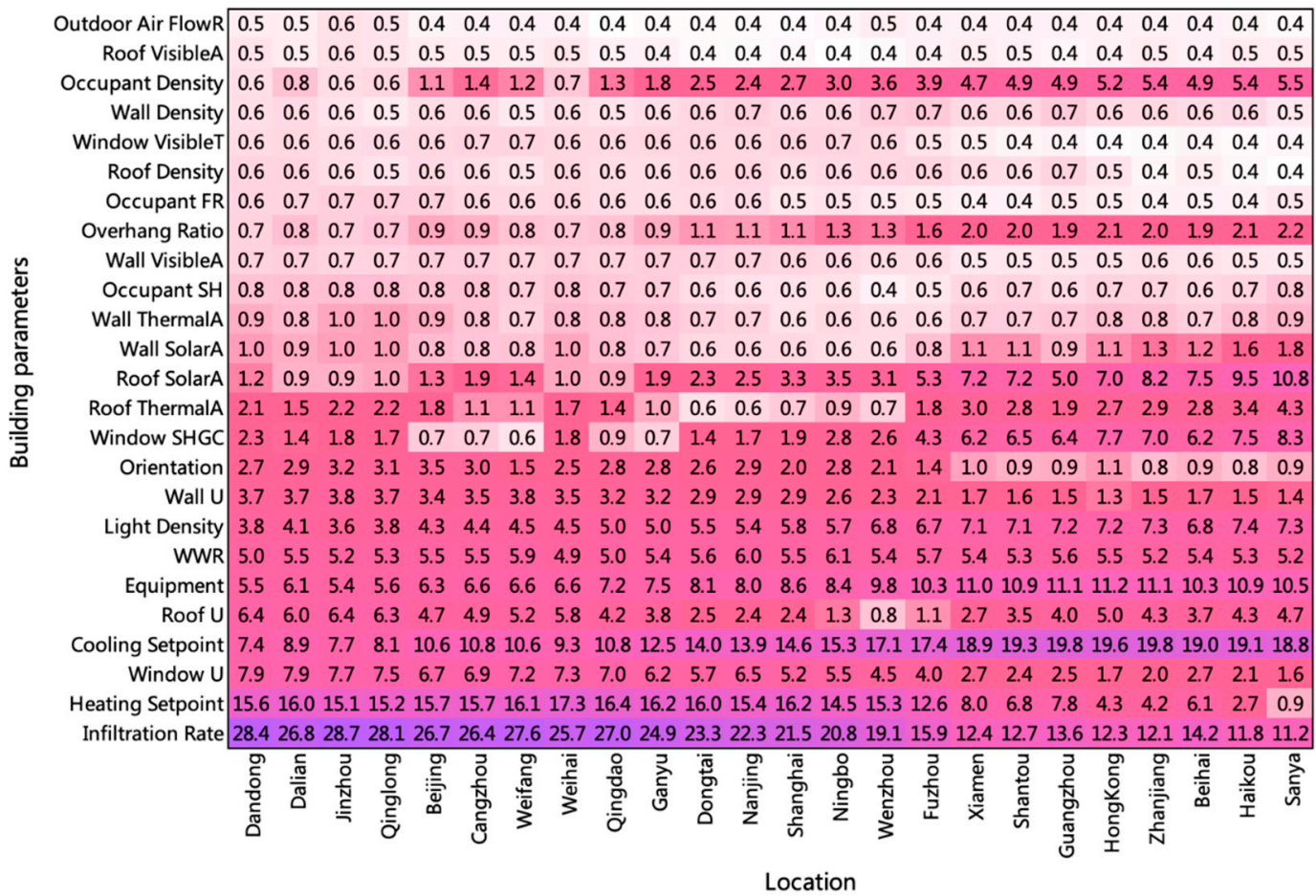

Figure 7. PI of input parameters in annual building energy consumption.

Figure 7 shows the analysis results of the influence index in 25 input parameters on annual total building energy consumption. The ranking of input parameters in the chart is determined by the PI of the first city. The parameters with the highest PI are ranked below, and the one with the lowest percentage is ranked above. The sum of influence values of all parameters in each city is $100 \%$. The detailed relationship of each parameter will be discussed in the next section.

The infiltration rate was the biggest factor affecting the total energy consumption in the northern cities. In Dandong, the impact of infiltration rate on total energy consumption was $28.4 \%$, which gradually decreased with the change of location from north to south and reached only $11.2 \%$ in Sanya. It is also worth noting that the PI of infiltration rate from Xiamen was maintained at about $12 \%$, indicating that the climate change with location is not obvious. The second influencing factor was the heating setpoint of the building. The 
influence index in Dandong was $15.6 \%$, which was significantly lower than the infiltration rate. With the change of location from north to south, it reached a maximum value of $17.3 \%$ in Weihai and then decreased to $0.9 \%$ in Sanya, which only ranked 16th among the 25 influencing parameters in Sanya.

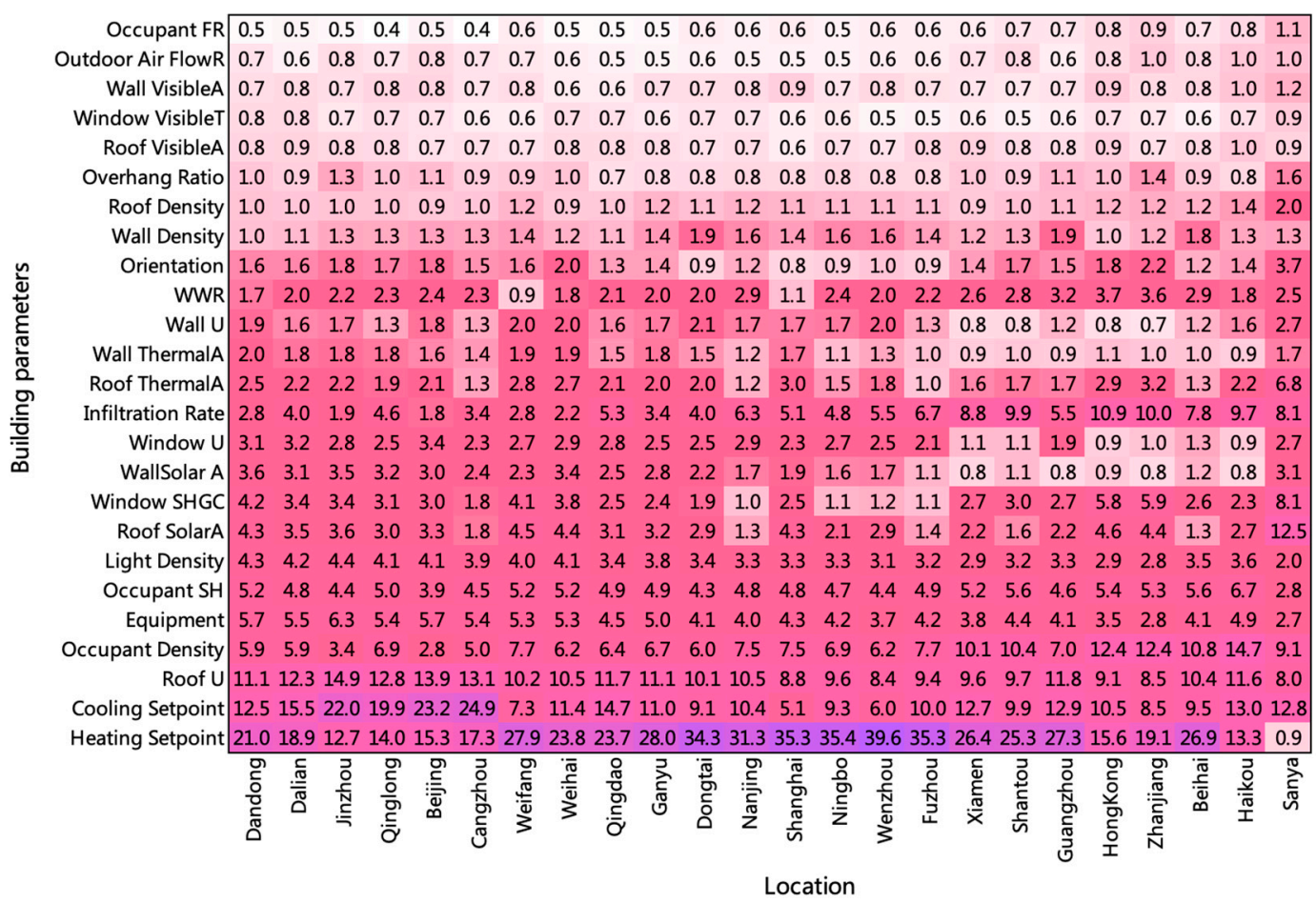

Figure 8. PI of input parameters in IUH.

The next parameters were the window $U$ value and cooling setpoint. The PI of window $\mathrm{U}$ value gradually decreased with the location moving southward, from $7.9 \%$ to $1.6 \%$, ranking from 3rd in Dandong to 13th in Sanya. However, the PI of the cooling setpoint increased from north to south and remained at $18.9 \%$ between Xiamen and Sanya. Interestingly, the percentages of heating and cooling setpoints on total energy consumption did not change from Xiamen, whose values were $12 \%$ and $19 \%$, respectively, where the cooling setpoint became the most influential factor on annual building energy consumption. Notably, roof solar absorptance in Dandong was only $1.2 \%$, making it the 13th influencing parameter, while it increased to $10.8 \%$ in Sanya.

In Figure 8, the average value of the IUH in each city is between $2800 \mathrm{~h}$ and $3200 \mathrm{~h}$; only Sanya reaches $3300 \mathrm{~h}$. In most cities, the heating setpoint has the greatest influence on $\mathrm{IUH}$, and the influence index between Shanghai and Fuzhou is greater than 35\%. Although the heating setpoint did not change with location, it reached $0.9 \%$ in Sanya, where it ranked as the second-lowest influencing factor. Furthermore, the cooling setpoint is the first influencing factor between Jinzhou and Cangzhou, which can exceed 20\% impact on IUH and was also maintained at more than $10 \%$ in other places. 


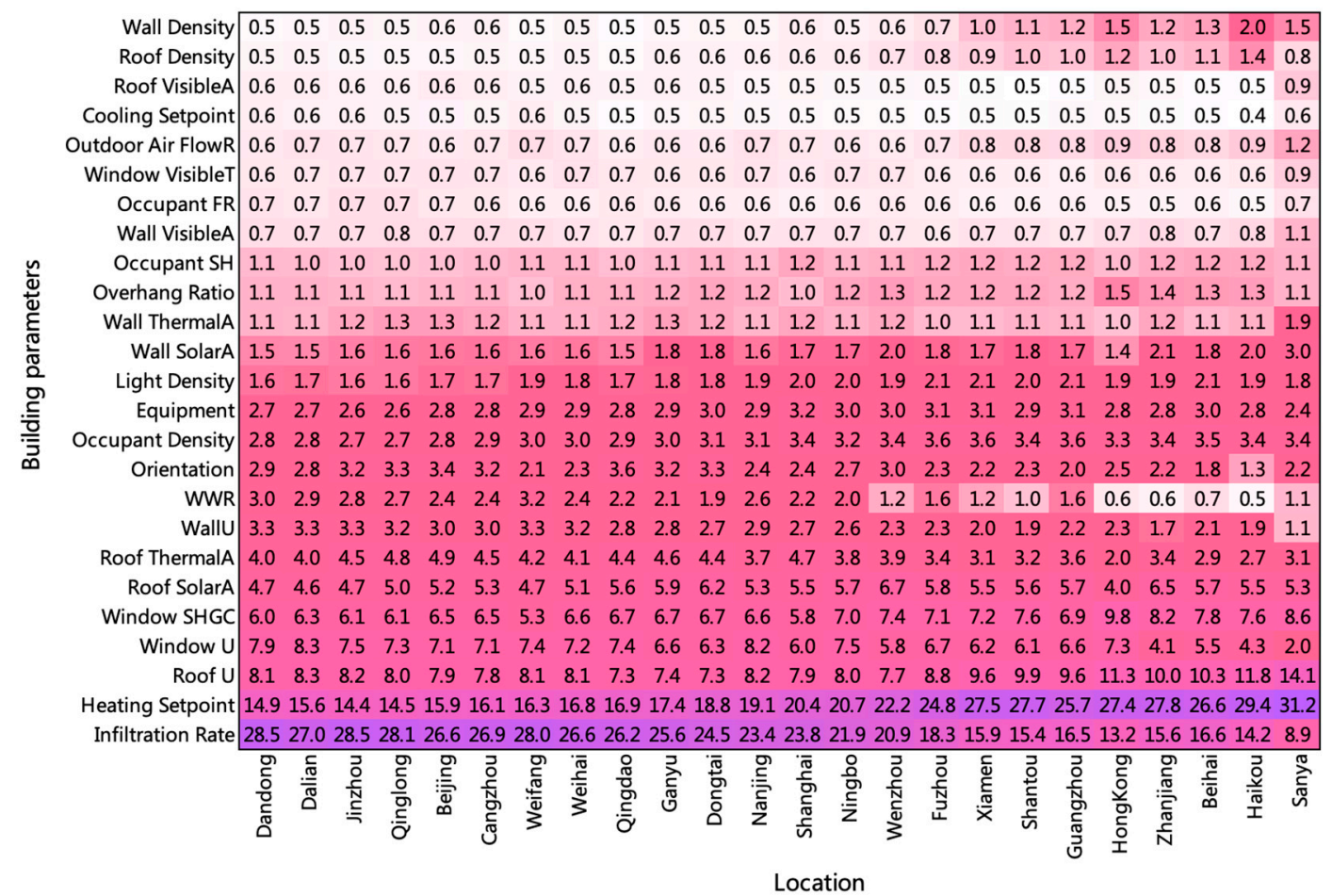

Figure 9. PI of input parameters in district heating demand.

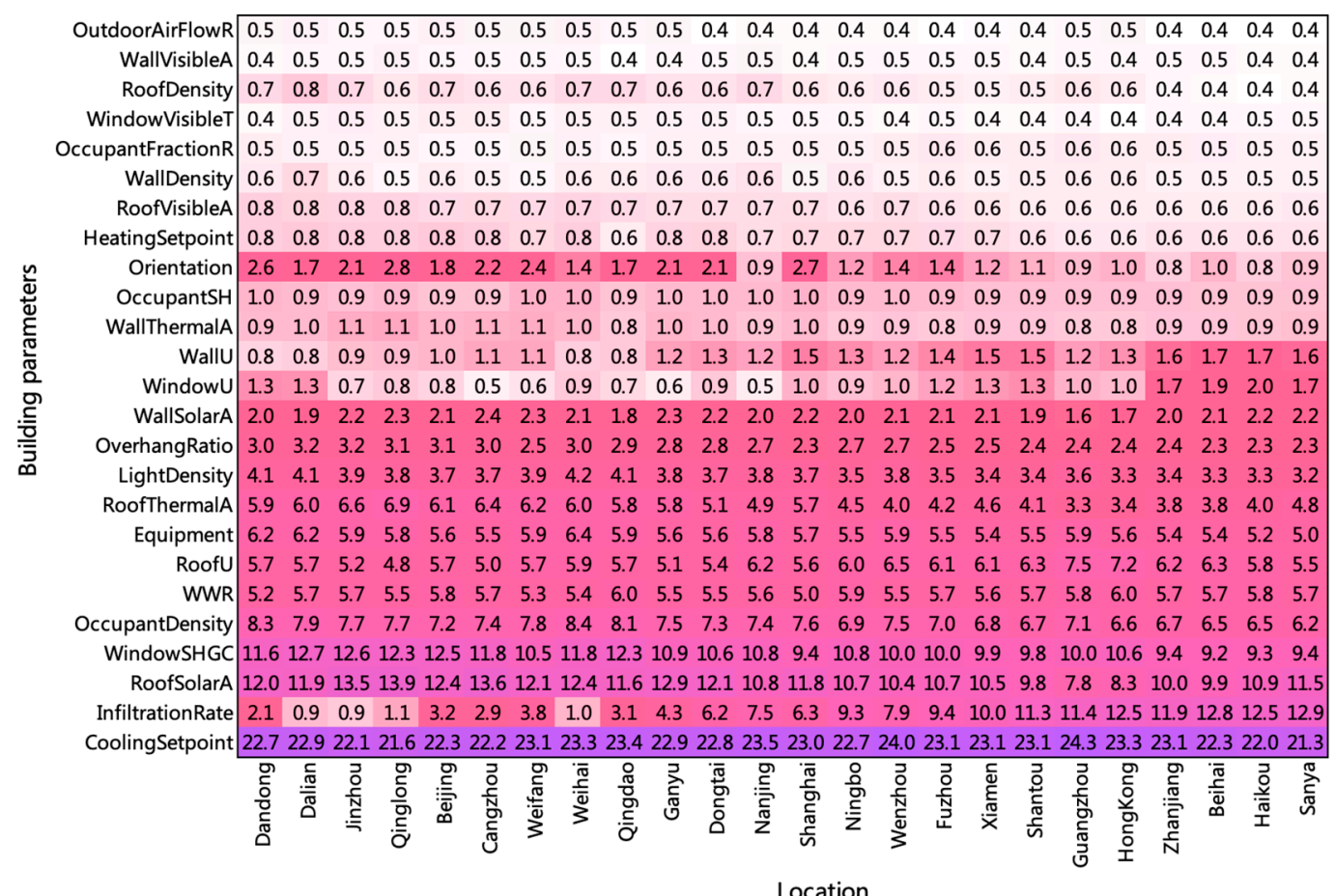

Figure 10. PI of input parameters in district cooling demand.

The PI of each parameter on the district heating demand is shown in Figure 9. Since district heating energy consumption approached zero after Xiamen, as shown in Figure 6, the research of important parameters should focus on northern cities. The PI of infiltration rate on district heating demand is similar to that of total energy consumption, reaching $28.5 \%$ in Dandong and $8.9 \%$ in Sanya. However, the heating setpoint increased from $14.9 \%$ in Dandong to $31.2 \%$ of Sanya, and the PI doubled. 
The fourth analysis chart is the PI of each input parameter with regard to district cooling demand. It should be noted that the energy consumption of district cooling demand in northern cities is small but increases as the location changes from north to south. The district cooling demand in Sanya is about four times that of Dandong, so the important parameters should be ranked in order starting with southernmost Sanya. In Figure 10, the largest influence factor of district cooling demand is the cooling setpoint in Sanya, with an PI of $21.3 \%$. However, the influence of the cooling setpoint does not change with geographical location and was maintained at the PI of $21-24 \%$ in these 24 coastal cities. The second parameter was infiltration rate, which had an impact of $12.9 \%$ on Sanya. The infiltration rate maintained a 10\% PI between Sanya and Xiamen but gradually declined as the location moved north, dropping to $0.9 \%$ in Jinzhou and Dalian.

\subsection{Analysis of Simulation Results in Different Sampling Methods}

The first step was to explore the impact of different sampling methods on building energy consumption because the logic of each sampling method is different. By comparing the simulation results of seven different sampling methods on an EnergyPlus model in a statistical box chart, the accuracy of the influence assessment of various SA methods on input parameters could be further realized. As shown in Figure 11, we analyzed the simulated values of annual total energy consumption of seven sampling methods and their comprehensive values in Qingdao, which is the real building location and the example used in this section. The average and median values of various sampling methods were similar, but we observed slight differences in the upper and lower quartiles and significant differences in the maximum and minimum values. FASTC and FASTE have a wider range of data because they periodically sample input data with sinusoidal function. Sobol's upper and lower quartiles and the gap between maximum and minimum were smaller than the FASTC and FASTE values. In the comparison of simulation results of LHS, QRS, and RS, the quartile value of LHS was the smallest, while the QRS had the smallest maximum and minimum values, and the change range of RS was the largest. On the other hand, the Morris sampling method differed from other numerical methods because it is a one-step-at-a-time method. Each parameter was sampled once, and only 260 samplings were performed in the simulation.

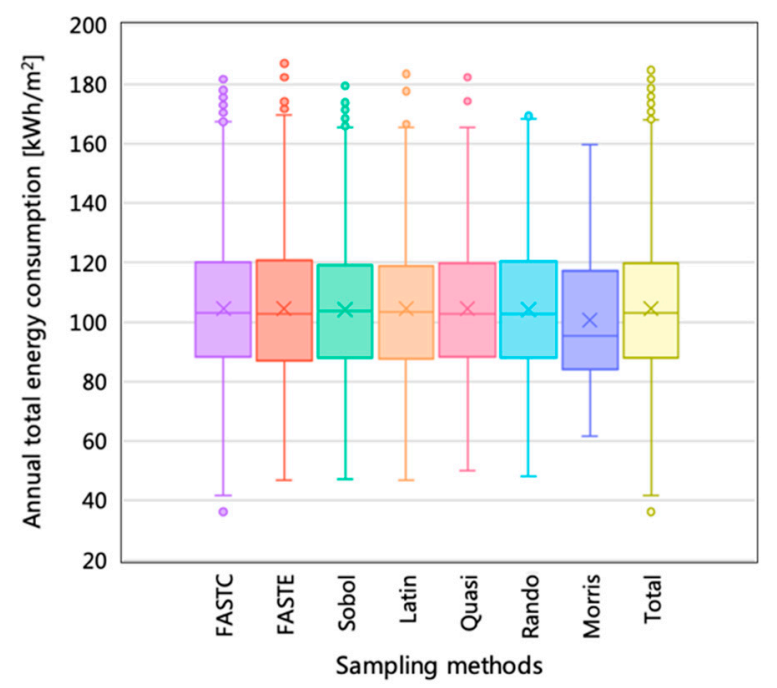

Figure 11. Simulation results of annual total building energy consumption in different sampling methods.

\subsection{Percentage Influence of Each SA Index}

In the second step, by averaging the percentage of all the factors in each city, we were able to obtain a comparison chart of the sensitivity method, as shown in Figure 12. Since the PIs of each factor analyzed by various sampling methods and SA methods differed, the average values of each parameter in the SA indices were calculated for comparison. The 
infiltration rate was still the most influential factor in the evaluation, and the average PI of all methods was $19.9 \%$. However, in the FASTC method, the extreme value of infiltration rate was $36.9 \%$, but it had a very low value in the KS sensitivity evaluation method, reaching $13.1 \%$ in KS of the RS method. The second most influential factor among these cities was the cooling setpoint, with an average influence value of $14.6 \%$. In the cooling setpoint factor, the Sobol method had the highest PI, which was $22.7 \%$ and $23.2 \%$. KS was still the lowest, reaching $10.2 \%$ in the LHS method, while the value in the FASTE method reached the maximum value of $21 \%$ and $16.8 \%$ in the evaluation of the heating setpoint, which even exceeded the infiltration rate to become the first influencing factor.

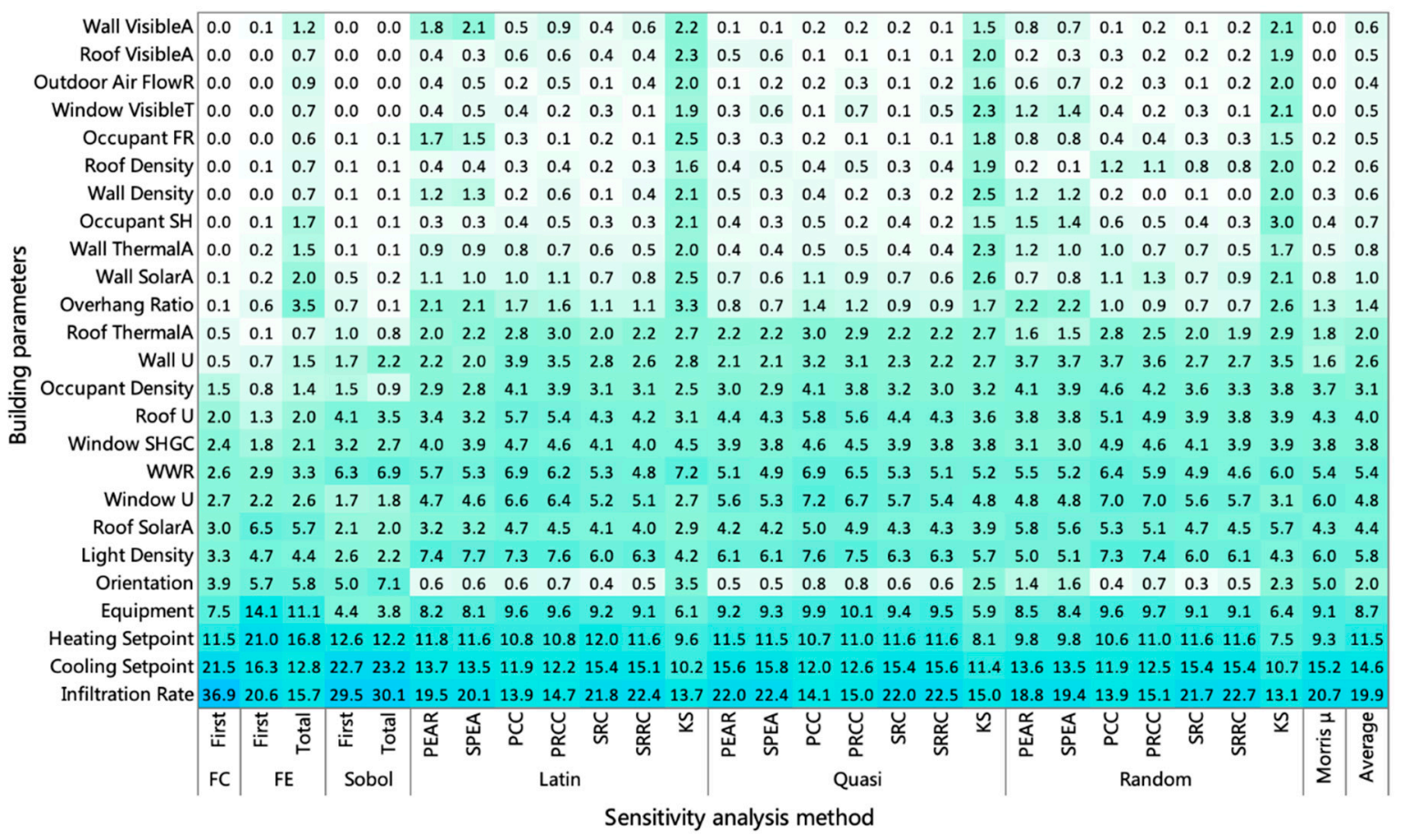

Figure 12. PI of input parameters in different sampling and SA methods.

\section{Discussion}

\subsection{Building Energy Consumption}

The building energy consumption were mainly influenced by infiltration rate, heating setpoint, window $\mathrm{U}$ value and cooling setpoint, which were the key parameters for policymakers to formulate the energy codes in the Chinese coastline. The PI of roof $U$ value differed from other factors, showing a parabola trend with climate change. It gradually decreased from north to south, from Dandong to Wenzhou and then continuously increased to Sanya. The PI of equipment and light density also increased from north to south, probably because the total energy consumption decreased from north to south, while the energy consumption of equipment and light density remained unchanged, but their proportion increased. Finally, the influence index of WWR changed little among the different locations, and the influence of window transmittance, roof solar absorptance, overhang ratio, and occupant density all showed an increasing trend from north to south, indicating that the influence of these parameters will increase as the climate temperature increases.

\subsection{Indoor Uncomfortable Hours}

For IUH, the heating setpoint was the biggest influence factor, while the cooling setpoint was the second influential parameter in most coastal cities. The subsequent important factors were roof $U$ value, occupant density, equipment usage, occupant sensible heat fraction, and light density. Thus, the setpoint of air conditioning, insulation of building, and internal gain should be considered important for the thermal comfort of occupants. As 
the topic of indoor comfort becomes more and more prevalent in the COVID-19 period, policymakers also need to consider the impact of these factors on future building comfort specifications. In most cities, their comprehensive impact on uncomfortable times can reach $30 \%$. It is worth noting that the influence of infiltration rate increased with the location from north to south. In Dandong, it only affects $2.8 \%$, ranking 12 th. However, it became more important in southern cities. For example, in Shantou, the influence index of infiltration rate was $9.9 \%$, making it the third largest value in input parameters. Because the average dry bulb temperature of Sanya is higher than that of other cities, the order of influencing factors also differs from other cities. For example, the most influential factors were cooling setpoint and roof solar absorptance in Sanya, with $12.8 \%$ and $12.5 \%$, respectively. This result indicated that when designing buildings in an area with high temperatures, rethinking the important parameters of IUH is a necessity.

\subsection{District Heating Demand}

District heating demand had contributed most of the building energy demand in north cities. Thus, for designers, the infiltration rate, heating setpoint, and roof $U$ value were the top three parameters to affect the percentage in each city, which can comprehensively impact about $50 \%$ of the district heating demand in the north part of the Chinese coastline. Therefore, the heating setpoint has a greater impact on district heating demand in the hotter locations, while the infiltration rate has a greater impact on district heating demand in the colder cities. As a result, the important influencing factors were found to be window $\mathrm{U}$ value, window SHGC, roof solar absorptance, roof thermal absorptance, wall $\mathrm{U}$ value, and WWR. These parameters mainly belong to the thermal insulation and absorptivity of windows, roofs, and walls, accounting for about $30 \%$ of the total in northern cities. With climate change, the district heating demand in winter increases significantly. Policymakers can pay attention to the key parameters mentioned in this section, which may affect $80 \%$ of the district heating demand along the northern coastline of China. Therefore, the annual heating demand is not only influenced by the climate condition but also affected by the building's thermal insulation performance.

\subsection{District Cooling Demand}

Due to the climate change and urban heat island, the district cooling demand has increased, especially in south cities. The key influential factor for district cooling demand in south cities were cooling setpoints, infiltration rate, and equipment density. The following influencing factors, such as the roof solar absorptance and the window SHGC, were not greatly affected by the location and remained around $10 \%$. Therefore, the cooling setpoint, roof solar absorptance, and window SHGC were not greatly affected by location, which can affect about $40 \%$ of the district cooling demand. In addition to the infiltration rate, orientation is also affected by location, but the impact ratio is low in the chart. Other factors are less affected by changing climate. Thus, for policymakers, the key parameters for the energy codes of district cooling demand in coastal cities were cooling setpoint, infiltration rate, roof solar absorptance, window SHGC, occupant density, WWR, roof U value, equipment usage, and roof thermal absorptance, which can comprehensively affect $80 \%$ of the district cooling demand.

\subsection{Identifying SA Methods}

To choose the most neutral and extensive influence assessment method, each sampling and sensitivity evaluation method had to be compared. We used the PI of annual building energy consumption to make comparisons in this section. In Figure 12, we found that the percentages of PEAR, SPEA, PCC, PRCC, SRC, and SRRC differed significantly from other evaluation methods in terms of the orientation on total building energy consumption. At the same time, the values of KS in three different sampling methods differed from other methods, which had relative mean values on various influencing factors, such as infiltration rate, heating, and cooling setpoint. On the one hand, it had a low evaluation 
value on the influential factors. On the other hand, the unimportant parameters obtained a high evaluation value in KS, such as the visibility absorptance of the wall and roof. In the comparison, FASTC and Sobol could distinguish the PI of each factor. The influential factor had a greater value, while the unimportant factor tended to be 0 . For example, they evaluated more than $30 \%$ influence of the infiltration rate, while the least influential factors, such as window visible transmittance, were close to $0.0 \%$. Therefore, the average PI of the 27 sensitivity evaluation methods used in this study can greatly reduce the impact of various extreme values from different sampling and SA methods and thus obtain a more accurate PI.

\subsubsection{F-Test}

In the evaluation of the F-test, the data set evaluated by each method was compared with the data set of the average value. Although the mean data set does not necessarily represent the most accurate sensitivity value, it can represent the most neutral, extensive, and reliable value. As shown in Figure 13, FASTC has the smallest value, followed by FASTE-first order, Sobol, and KS in each sampling method. Therefore, they are the most different evaluation methods from the average data set. Then, we observed FASTE-total order and the PCC and PRCC in three sampling methods, and their F-test values were in the middle of the chart, which were still close to the average data set. The rest of the PEAR, SPEA, SRC, SRRC, and Morris methods had an F-test value above 0.7, among which SRC, SRRC, and Morris have been widely used SA methods in many studies. Among them, the two largest values of the F-test were PEAR in the QRS and LHS methods, which reached 0.82 and 0.8 , which were the closest to the average data set. Meanwhile, the SRC of the RS and LHS methods were 0.79 and 0.78 , respectively. Therefore, the recommended SA indices in the F-test part were Quasi-PEAR, Random-SRC, and Latin-PEAR.

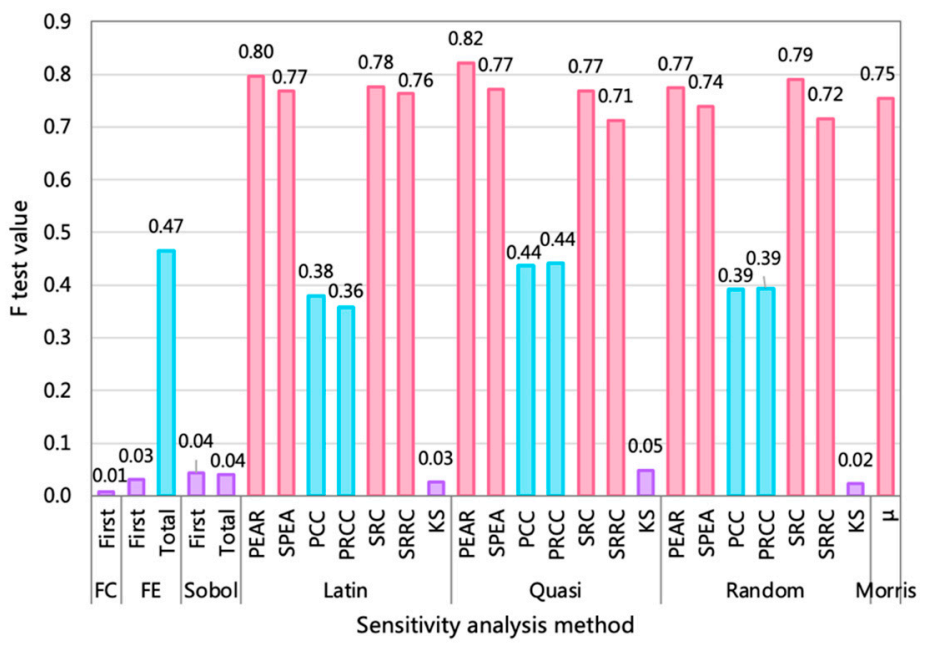

Figure 13. F-test values in different sampling and SA methods.

\subsubsection{Exceed Percentage}

We then added up the difference between the influence value and the average value of the factors in each method to obtain the cumulative percentage difference between each method and the average data set. The values in Figure 14 consider the mean percentage value of four outputs in this paper, so the smaller the difference between the data set and the average set, the more accurate the data is to the average. The results in Figure 14 are similar to those in the F-test. The exceed percentages of FASTC, FASTE, Sobol, and KS are all over $40 \%$, the largest cumulative difference from the average data set. The second level includes PCC, PRCC, and Morris, which all had a cumulative average gap between $20 \%$ and $30 \%$. Finally, the PEAR, SPEA, SRC, and SRRC were all less than $20 \%$. The smallest of them were SRRC and SRC in the LHS method, with values of $12.2 \%$ and $12.9 \%$, respectively. PEAR in the QRS method was $13.0 \%$, while the SRC in the RS method was $13.1 \%$. 


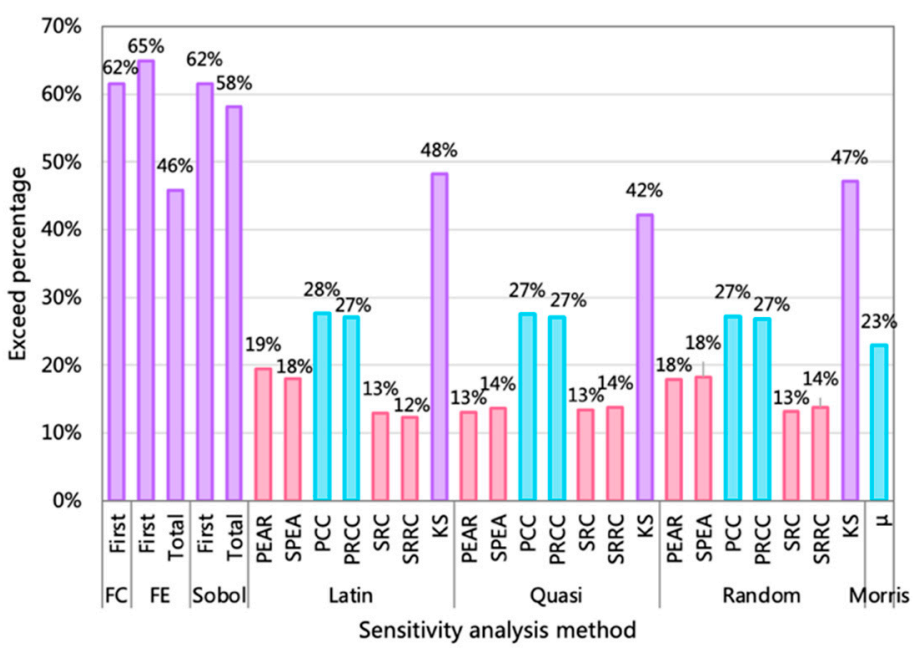

Figure 14. Exceed percentage values in different sampling and SA methods.

Therefore, we found that the best SA method and sampling was PEAR in the QRS method, followed by SRC in the QS and LHS methods, which can obtain the closest data to the average. However, since these methods require a long simulation time, the Morris method was also able to get close results if researchers needed to save time. Furthermore, we have shown that different sampling and SA methods can differ considerably. If these methods are considered comprehensively, the objective influence value can be obtained.

\section{Conclusions}

In this paper, we proposed a new approach for evaluating the comprehensive PI of input parameters on building energy and comfort performance and a way for exploring the most reliable sampling and sensitivity assessment method. Using a variety of sampling methods and sensitivity evaluation methods, we comprehensively evaluated the impact of 25 input parameters on annual total building energy consumption, IUH, and district heating and cooling energy demand in 24 coastal cities of China. The 27 sensitivity indices were integrated by using the influence index formula to obtain the accurate PI of each input parameter under the corresponding conditions. The paper can be concluded into six points:

(1) Comprehensive key parameters: For all four output factors of the results, the key parameters were heating setpoint, infiltration rate, cooling setpoint, roof $U$ value, roof solar absorptance, window SHGC, equipment, and occupant density, which comprehensively impacted $70 \%$ of the four outputs of energy demand and comfort performance along China's coastline. Therefore, these eight important parameters need to be considered in the design stage of building along the Chinese coastline. We also found that the PI of many input parameters is affected by location.

(2) Annual total building energy consumption: The infiltration rate was the biggest influence factor in the northern cities, impacting $28.4 \%$ of total building energy in Dandong and gradually decreasing with the change of the location from north to south, reaching only $11.2 \%$ in Sanya. The subsequent important factors were heating setpoint, window $U$ value, cooling setpoint, roof $U$ value, and equipment, which were able to affect more than $40 \%$ of annual building energy consumption.

(3) Indoor comfort: Heating and cooling setpoints were the two biggest influence factors on IUH, accounting for $40 \%$ in most cities. The subsequent important factors were roof $U$ value, occupant density, equipment usage, occupant sensible heating ratio, and light density, whose comprehensive impact on IUH could reach $30 \%$. Sanya, the hottest city, had different influence results with other cities regarding IUH.

(4) District heating demand: This contributed nearly $70 \%$ of the energy consumption in the northernmost city, which dropped to nearly $12.5 \%$ in Xiamen. The infiltration 
rate also affected more than $25 \%$ of district heating energy demand in northern cities. The heating setpoint, roof $U$ value, window $U$ value, window SHGC value, roof solar and thermal absorptance, are six other top parameters affecting the influence index and can comprehensively impact approximately $45 \%$ of the district heating energy demand in the northernmost city.

(5) District cooling demand: This consumed less energy than the heating demand and produced $9.6 \%$ and $76.3 \%$ of total building energy consumption in Dandong and Sanya, respectively. The cooling setpoint was the largest influence factor and did not change with geographical location, which had maintained the PI of $21-24 \%$ in all 24 cities. The following factors, such as infiltration rate, roof solar absorptance, window SHGC, and occupant density altogether could affect more than $40 \%$ of the district cooling demand in southern cities.

(6) Reliable SA method: The PI of parameters showed a huge difference between each sampling and SA method. After comparing the F-test and the exceed percentage test, the PEAR method in the QRS method was proposed as the most reliable method in the study. It is followed by SRC in the RS and LHS methods, which obtained the closest data to the average value. Meanwhile, the Morris is also a recommended method because it can reduce considerable simulation time but still obtain a close result.

Importantly, the results of this research could provide suggestions for policymakers to formulate the relevant building codes, and the proposed method can also be applied by other researchers. However, this study has some limitations. At first, although the case building was a real office building, the study used a single building model to analyze the PI, which may reduce the likelihood of our results in other types of office models. Second, the simulation process was tedious and required several months. Each city needed to be sampled and simulated more than 20,000 times. Third, like many types of SA research, since current knowledge about the building factors and their boundaries are still limited, the number of input parameters and their ranges need to be extended. Future research may add different building models and locations and use an artificial neural network to predict the PI of each parameter, in order to save the modeling and simulation time and facilitate designers and engineers who are not familiar with building software in querying and obtaining the influence value of each input parameter.

Author Contributions: Conceptualization, Y.-S.T. and R.C.; methodology, Y.-S.T. and R.C.; software, R.C.; validation, Y.-S.T. and R.C.; data curation, R.C.; writing-original draft preparation, R.C.; writing-review and editing, Y.-S.T.; visualization, R.C.; supervision, Y.-S.T. Both authors have read and agreed to the published version of the manuscript.

Funding: This research received no external funding.

Institutional Review Board Statement: Not applicable.

Informed Consent Statement: Not applicable.

Data Availability Statement: The data presented in this study are available on request from the corresponding author.

Conflicts of Interest: The authors declare no conflict of interest.

\section{References}

1. Degirmenci, K.; Desouza, K.C.; Fieuw, W.; Watson, R.T.; Yigitcanlar, T. Understanding policy and technology responses in mitigating urban heat islands: A literature review and directions for future research. Sustain. Cities Soc. 2021, 70, 102873. [CrossRef]

2. Cao, X.; Dai, X.; Liu, J. Building energy-consumption status worldwide and the state-of-the-art technologies for zero-energy buildings during the past decade. Energy Build. 2016, 128, 198-213. [CrossRef]

3. U.S. Environmental Protection Agency. Report to Congress on Indoor Air Quality; U.S. Environmental Protection Agency: Washington, DC, USA, 1989; Volume 2.

4. Pérez-Lombard, L.; Ortiz, J.; Pout, C. A review on buildings energy consumption information. Energy Build. 2008, 40, 394-398. [CrossRef] 
5. Wu, Z.; Li, N.; Wargocki, P.; Peng, J.; Li, J.; Cui, H. Field study on thermal comfort and energy saving potential in 11 split air-conditioned office buildings in Changsha, China. Energy 2019, 182, 471-482. [CrossRef]

6. Chen, J.; Lu, L. Comprehensive evaluation of thermal and energy performance of radiative roof cooling in buildings. J. Build. Eng. 2021, 33, 101631. [CrossRef]

7. Zeferina, V.; Wood, F.R.; Edwards, R.; Tian, W. Sensitivity analysis of cooling demand applied to a large office building. Energy Build. 2021, 235, 110703. [CrossRef]

8. Zhang, Y.; Zhang, X.; Huang, P.; Sun, Y. Global sensitivity analysis for key parameters identification of net-zero energy buildings for grid interaction optimization. Appl. Energy 2020, 279, 115820. [CrossRef]

9. Andolsun, S.; Culp, C.H.; Haberl, J.S.; Witte, M.J. EnergyPlus vs. DOE-2.1e: The effect of ground coupling on cooling/heating energy requirements of slab-on-grade code houses in four climates of the US. Energy Build. 2012, 52, 189-206. [CrossRef]

10. Mun, S.H.; Kang, J.; Kwak, Y.; Jeong, Y.S.; Lee, S.M.; Huh, J.H. Limitations of EnergyPlus in analyzing energy performance of semi-transparent photovoltaic modules. Case Stud. Therm. Eng. 2020, 22, 100765. [CrossRef]

11. Pandey, B.; Banerjee, R.; Sharma, A. Coupled EnergyPlus and CFD analysis of PCM for thermal management of buildings. Energy Build. 2021, 231, 110598. [CrossRef]

12. Ji, Y.; Lee, A.; Swan, W. Building dynamic thermal model calibration using the Energy House facility at Salford. Energy Build. 2019, 191, 224-234. [CrossRef]

13. Čekon, M. Accuracy analysis of longwave sky radiation models in the MZELWE module of the ESP-r program. Energy Build. 2015, 103, 147-158. [CrossRef]

14. Mazzeo, D.; Matera, N.; Cornaro, C.; Oliveti, G.; Romagnoni, P.; De Santoli, L. EnergyPlus, IDA ICE and TRNSYS predictive simulation accuracy for building thermal behaviour evaluation by using an experimental campaign in solar test boxes with and without a PCM module. Energy Build. 2020, 212, 109812. [CrossRef]

15. Zhu, L.; Wang, B.; Sun, Y. Multi-objective optimization for energy consumption, daylighting and thermal comfort performance of rural tourism buildings in north China. Build. Environ. 2020, 176, 106841. [CrossRef]

16. Pang, Z.; O'Neill, Z.; Li, Y.; Niu, F. The role of sensitivity analysis in the building performance analysis: A critical review. Energy Build. 2020, 209, 109659. [CrossRef]

17. Im, P.; Jackson, R.; Bae, Y.; Dong, J.; Cui, B. Probabilistic reliability assessment and case studies for predicted energy savings in residential buildings. Energy Build. 2020, 209, 109658. [CrossRef]

18. Ding, Y.; Fan, L.; Liu, X. Analysis of feature matrix in machine learning algorithms to predict energy consumption of public buildings. Energy Build. 2021, 249, 111208. [CrossRef]

19. Asadi, E.; Da Silva, M.G.; Antunes, C.H.; Dias, L. Multi-objective optimization for building retrofit strategies: A model and an application. Energy Build. 2012, 44, 81-87. [CrossRef]

20. Carli, R.; Dotoli, M.; Pellegrino, R.; Ranieri, L. Using multi-objective optimization for the integrated energy efficiency improvement of a smart city public buildings' portfolio. In Proceedings of the 2015 IEEE International Conference on Automation Science and Engineering (CASE), Gothenburg, Sweden, 24-28 August 2015; pp. 21-26. [CrossRef]

21. Carli, R.; Dotoli, M.; Pellegrino, R.; Ranieri, L. A Decision Making Technique to Optimize a Buildings' Stock Energy Efficiency. IEEE Trans. Syst. Man Cybern. Syst. 2017, 47, 794-807. [CrossRef]

22. Wei, T. A review of sensitivity analysis methods in building energy analysis. Renew. Sustain. Energy Rev. 2013, 20, 411-419. [CrossRef]

23. Ebrahimi-Moghadam, A.; Ildarabadi, P.; Aliakbari, K.; Fadaee, F. Sensitivity analysis and multi-objective optimization of energy consumption and thermal comfort by using interior light shelves in residential buildings. Renew. Energy 2020, 159, 736-755. [CrossRef]

24. Alsharif, R.; Arashpour, M.; Chang, V.; Zhou, J. A review of building parameters' roles in conserving energy versus maintaining comfort. J. Build. Eng. 2021, 35, 102087. [CrossRef]

25. Guo, R.; Hu, Y.; Liu, M.; Heiselberg, P. Influence of design parameters on the night ventilation performance in office buildings based on sensitivity analysis. Sustain. Cities Soc. 2019, 50, 101661. [CrossRef]

26. Delgarm, N.; Sajadi, B.; Azarbad, K.; Delgarm, S. Sensitivity analysis of building energy performance: A simulation-based approach using OFAT and variance-based sensitivity analysis methods. J. Build. Eng. 2018, 15, 181-193. [CrossRef]

27. Mauro, G.M.; Hamdy, M.; Vanoli, G.P.; Bianco, N.; Hensen, J.L.M. A new methodology for investigating the cost-optimality of energy retrofitting a building category. Energy Build. 2015, 107, 456-478. [CrossRef]

28. Rasouli, M.; Ge, G.; Simonson, C.J.; Besant, R.W. Uncertainties in energy and economic performance of HVAC systems and energy recovery ventilators due to uncertainties in building and HVAC parameters. Appl. Therm. Eng. 2013, 50, 732-742. [CrossRef]

29. Pannier, M.L.; Schalbart, P.; Peuportier, B. Comprehensive assessment of sensitivity analysis methods for the identification of influential factors in building life cycle assessment. J. Clean. Prod. 2018, 199, 466-480. [CrossRef]

30. Menberg, K.; Heo, Y.; Choudhary, R. Sensitivity analysis methods for building energy models: Comparing computational costs and extractable information. Energy Build. 2016, 133, 433-445. [CrossRef]

31. Vartholomaios, A. A parametric sensitivity analysis of the influence of urban form on domestic energy consumption for heating and cooling in a Mediterranean city. Sustain. Cities Soc. 2017, 28, 135-145. [CrossRef]

32. Sayah, T. Adaptive stratified Monte Carlo algorithm for numerical computation of integrals. Math. Comput. Simul. 2019, 157, 143-158. [CrossRef] 
33. Navid, A.; Khalilarya, S.; Abbasi, M. Diesel engine optimization with multi-objective performance characteristics by nonevolutionary Nelder-Mead algorithm: Sobol sequence and Latin hypercube sampling methods comparison in DoE process. Fuel 2018, 228, 349-367. [CrossRef]

34. Torii, A.J. On sampling-based schemes for probability of failure sensitivity analysis. Probabilistic Eng. Mech. 2020, 62, 103099. [CrossRef]

35. Zhang, F.; Cheng, L.; Wu, M.; Xu, X.; Wang, P.; Liu, Z. Performance analysis of two-stage thermoelectric generator model based on Latin hypercube sampling. Energy Convers. Manag. 2020, 221, 113159. [CrossRef]

36. Saleem, M.; Hosoda, A. Latin Hypercube Sensitivity Analysis and Non-destructive Test to Evaluate the Pull-out Strength of Steel Anchor Bolts Embedded in Concrete. Constr. Build. Mater. 2021, 290, 123256. [CrossRef]

37. Hou, T.; Nuyens, D.; Roels, S.; Janssen, H. Quasi-Monte Carlo based uncertainty analysis: Sampling efficiency and error estimation in engineering applications. Reliab. Eng. Syst. Saf. 2019, 191, 106549. [CrossRef]

38. Ökten, G.; Liu, Y. Randomized quasi-Monte Carlo methods in global sensitivity analysis. Reliab. Eng. Syst. Saf. 2021, 210, 107520. [CrossRef]

39. Nguyen, A.T.; Reiter, S. A performance comparison of sensitivity analysis methods for building energy models. Build. Simul. 2015, 8, 651-664. [CrossRef]

40. Tian, W.; De Wilde, P. Uncertainty and sensitivity analysis of building performance using probabilistic climate projections: A UK case study. Autom. Constr. 2011, 20, 1096-1109. [CrossRef]

41. Sreedevi, S.; Eldho, T.I. A two-stage sensitivity analysis for parameter identification and calibration of a physically-based distributed model in a river basin. Hydrol. Sci. J. 2019, 64, 701-719. [CrossRef]

42. Yang, S.; Fiorito, F.; Prasad, D.; Sproul, A.; Cannavale, A. A sensitivity analysis of design parameters of BIPV/T-DSF in relation to building energy and thermal comfort performances. J. Build. Eng. 2021, 41, 102426. [CrossRef]

43. Pianosi, F.; Wagener, T. A simple and efficient method for global sensitivity analysis based oncumulative distribution functions. Environ. Model. Softw. 2015, 67, 1-11. [CrossRef]

44. Kim, M.K.; Kim, Y.S.; Srebric, J. Predictions of electricity consumption in a campus building using occupant rates and weather elements with sensitivity analysis: Artificial neural network vs. linear regression. Sustain. Cities Soc. 2020, 62, 102385. [CrossRef]

45. Lim, H.; Zhai, Z.J. Comprehensive evaluation of the influence of meta-models on Bayesian calibration. Energy Build. 2017, 155, 66-75. [CrossRef]

46. Mechri, H.E.; Capozzoli, A.; Corrado, V. USE of the ANOVA approach for sensitive building energy design. Appl. Energy 2010, 87, 3073-3083. [CrossRef]

47. Antoniadis, A.; Lambert-Lacroix, S.; Poggi, J.M. Random forests for global sensitivity analysis: A selective review. Reliab. Eng. Syst. Saf. 2021, 206, 107312. [CrossRef]

48. Xiao, S.; Oladyshkin, S.; Nowak, W. Forward-reverse switch between density-based and regional sensitivity analysis. Appl. Math. Model. 2020, 84, 377-392. [CrossRef]

49. Pang, Z.; O'Neill, Z. Uncertainty quantification and sensitivity analysis of the domestic hot water usage in hotels. Appl. Energy 2018, 232, 424-442. [CrossRef]

50. Wang, X.; Jin, X.; Yin, Y.; Shi, X.; Zhou, X. A transient heat and moisture transfer model for building materials based on phase change criterion under isothermal and non-isothermal conditions. Energy 2021, 224, 120112. [CrossRef]

51. Yildiz, Y.; Arsan, Z.D. Identification of the building parameters that influence heating and cooling energy loads for apartment buildings in hot-humid climates. Energy 2011, 36, 4287-4296. [CrossRef]

52. Ascione, F.; Bianco, N.; Iovane, T.; Mauro, G.M.; Napolitano, D.F.; Ruggiano, A.; Viscido, L. A real industrial building: Modeling, calibration and Pareto optimization of energy retrofit. J. Build. Eng. 2020, 29, 101186. [CrossRef]

53. Ghahramani, A.; Zhang, K.; Dutta, K.; Yang, Z.; Becerik-Gerber, B. Energy savings from temperature setpoints and deadband: Quantifying the influence of building and system properties on savings. Appl. Energy 2016, 165, 930-942. [CrossRef]

54. Tian, W.; de Wilde, P.; Li, Z.; Song, J.; Yin, B. Uncertainty and sensitivity analysis of energy assessment for office buildings based on Dempster-Shafer theory. Energy Convers. Manag. 2018, 174, 705-718. [CrossRef]

55. Luerssen, C.; Verbois, H.; Gandhi, O.; Reindl, T.; Sekhar, C.; Cheong, D. Global sensitivity and uncertainty analysis of the levelised cost of storage (LCOS) for solar-PV-powered cooling. Appl. Energy 2021, 286, 116533. [CrossRef]

56. Chinese Shandong Department of Housing and Urban Rural Development. Design Standard for Energy Efficiency of Public Buildings; Shandong Construction Development Research Institute: Jinan, China, 2019; DB 37/5155-2019.

57. Chinese Shandong Department of Housing and Urban Rural Department. Applicationn Technical Specification of External Wall Thermal Insulation; Shandong Construction Development Research Institute: Jinan, China, 2012; DBJ/T 14-085-2012.

58. Li, H.; Wang, S.; Cheung, H. Sensitivity analysis of design parameters and optimal design for zero/low energy buildings in subtropical regions. Appl. Energy 2018, 228, 1280-1291. [CrossRef]

59. Bordbari, M.J.; Seifi, A.R.; Rastegar, M. Probabilistic energy consumption analysis in buildings using point estimate method. Energy 2018, 142, 716-722. [CrossRef]

60. Ciardiello, A.; Rosso, F.; Dell'Olmo, J.; Ciancio, V.; Ferrero, M.; Salata, F. Multi-objective approach to the optimization of shape and envelope in building energy design. Appl. Energy 2020, 280, 115984. [CrossRef]

61. Ministry of Housing and Urban Rural Development of China. Uniform Standard for Design of Civil Buildings; China Institute of Building Standard Design and Research: Beijing, China, 2019; GB 50352-2019. 